\title{
Yönetim Bilişim Sistemleri Disiplininde Hazırlanan Lisansüstü Tezlerin Gizli Dirichlet Ayrımı Algoritmasıla Konu Modellemesi
}

\author{
Levent ÇALLI ${ }^{1}$, Fatih ÇALLI ${ }^{2}$ ve Büssra ALMA ÇALLI ${ }^{3}$ \\ Öz
}

Yönetim Bilişim Sistemlerinin etkilendiği branşlar, alanda geliştirilen teoriler ve var olan konu çeşitliliklerinin belirlenmesi bir disiplin olarak tanımlandığ ilk günden bu yana akademik literatürde yoğun olarak tartış1lan bir konudur. Bu araştırmada, Türkiye'de hızlı ve dinamik bir gelişim gösteren YBS anabilim dalında 2002-2020 yılları arasında tamamlanan 574 lisansüstü tez özeti metin madenciliği yöntemi olan Gizli Dirichlet Ayrımı algoritmasıyla analiz edilmiștir. Analiz sonucunda tezlerin; e-Ticaret ve Pazarlama, Sistem Geliștirme ve Etkileri, Bilișim Sistemleri'nin Organizasyonlara Etkileri, Veri Madenciliği, İnsan Kaynakları Yönetimi, Organizasyonel Değişim, Alana Özel Çalışmalar I, Alana Özel Çalışmalar II, Güvenlik, Eğitim ve Öğretim, Tahmin ve Karar Destek olmak üzere 11 farklı konu başlığı altında kümelenebileceği öngörülmektedir. Araştırma kapsamında, tahmin sonuçlarının ulusal ve uluslararası literatürle göstermiş olduğu benzerlikler ve farklılıklar tartışılmıştır. Araştırma sonucunda yönetim bilişim sistemleri üzerine çalışma yapmak isteyen araştırmacılara fikir vermek ve yol göstermek hedeflenmiştir.

Anahtar Kelimeler: Yönetim Bilişim Sistemleri, Metin Madenciliği, Konu Modelleme, Gizli Dirichlet Ayrımı

Topic Modeling of Postgraduate Theses in Management Information Systems Discipline with Latent Dirichlet Allocation (LDA) Algorithm

\begin{abstract}
The disciplines that affect the theories developed in the field, and the identification of the existing topic diversity have all been extensively discussed in the academic literature since the Management Information Systems (MIS) was first defined as a discipline. In this study, 574 postgraduates' theses completed between 2002 and 2020 in the Department of MIS were analyzed using the Hidden Dirichlet Discrimination algorithm, which is a text mining method. As a result of the analysis, it is predicted that postgraduates' theses can be clustered under 11 topics, are eCommerce and Marketing $\left(\mathrm{K}_{1}\right)$, System Development and Effects $\left(\mathrm{K}_{2}\right)$, Effects of Information Systems on Organizations $\left(K_{3}\right)$, Data Mining $\left(K_{4}\right)$, Human Resources Management $\left(K_{5}\right)$, Organizational Change $\left(K_{6}\right)$, FieldSpecific Studies I $\left(K_{7}\right)$, Field-Specific Studies II $\left(K_{9}\right)$, Security $\left(K_{8}\right)$, Education and Training $\left(K_{10}\right)$, Forecasting and Decision Support $\left(\mathrm{K}_{11}\right)$. The similarities and differences of the results are discussed in the context of the national and international literature. As a result of the research, it was aimed to give an idea and guide the researchers who want to study on management information systems.
\end{abstract}

Key Words: Management Information Systems, Text Mining, Topic Modelling, Latent Dirichlet Allocation

\section{Atıf İçin / Please Cite As:}

Çallı, L., Çallı, F. ve Alma Çallı, B. (2021). Yönetim bilişim sistemleri disiplininde hazırlanan lisansüstü tezlerin gizli dirichlet ayrımı algoritmasıyla konu modellemesi. Manas Sosyal Arastırmalar Dergisi, 10(4), 2355-2372.

Geliş Tarihi / Received Date: 10.03.2021

Kabul Tarihi / Accepted Date: 03.06.2021

\footnotetext{
${ }^{1}$ Dr. Öğr. Üyesi - Türkiye -Sakarya Üniversitesi, lcalli@sakarya.edu.tr

(iD) ORCID: 0000-0003-2221-1469

${ }^{2}$ Dr. Öğr. Üyesi - Türkiye -Sakarya Üniversitesi, fcalli@sakarya.edu.tr

ORCID: 0000-0003-2508-3853

${ }^{3}$ Dr. Arş. Gör. - Türkiye -Sakarya Üniversitesi, busraalma@sakarya.edu.tr

iD ORCID: 0000-0001-7411-4295
} 


\section{Giriş}

1890 y1lında delikli kartların icadıyla anılmaya başlanan bilişim sistemleri günümüze gelene kadar birçok farklı teknolojik gelişme ile hayatın her evresinde önemli bir konuma ulaşmıştır (Campbell-Kelly, 1996, s.23). Bu gelişmeler doğal olarak hem dünyada hem de Türkiye'de bilişim sistemlerinin yönetimi konusunda akademik oluşumların başlamasını sağlamıştır. Öncelikle mühendislik disiplini ile hareket etmeye çalışan bilişim sistemleri yönetimi, disiplinlerarası birçok farklı konunun dikkate alınmasını gerektiğinden dolayı kendine has bir disiplin olan "Yönetim Bilişim Sistemleri”" (YBS) disiplinini ortaya çıkarmıştır. YBS; yönetim, bilişim, bilgi teknolojileri stratejileri, bu teknolojilerin kullanımı ve örgütsel değişim ile bütünleşmesi konularını temel alan birçok akademik disiplinin kesişme noktası olan disiplinlerarası yeni bir disiplin olarak tanımlanmaktadır (Bensghir, 2002, s. 77). Ülkemizde YBS disiplininin gelişimi 1991 yllnnda Marmara Üniversitesi İşletme Enformatiği ve 1995 yllında Boğaziçi Üniversitesi YBS bölümü ile gerçekleşmiş ve takip eden yıllarda üniversitelerin çeşitli fakültelerinde verilen eğitimlerle gelişimini sürdürmüştür (Emre ve Kıran, 2019, s. 424). İlk dönemlerde bilgisayar mühendisliği bölümlerinde tanımlanan bilişim kavramı üzerine yapılan lisansüstü çalışmalar ilerleyen yıllarda YBS bilim dalları ve ana bilim dallarının kurulmasıyla disiplinlerarası kimliğine kavuşmuştur.

Literatürde, bilişim, bilgi ve veri kavramlarının benzer şekillerde kullanılması, bu kavramlar arasındaki farkların kelime anlamı özelinde açıkça ortaya konulmasını gerektirmektedir. Veri (data) kaydedilebilir, yakalanabilir ve saklanabilir semboller ile sinyal okumaları olarak tanımlamıştır. Sembollerin kelimeler, sayılar, diyagramlar ve görüntülerden oluştuğu; sinyallerin ise 1şık, ses, koku, tat ve dokunma duyusal okumalarından meydana geldiğini ifade edilmektedir (Liew, 2007, s. 2). Semboller olarak veri, içsel anlamın depolanmasıdır, bu açıdan yalnızca bir temsildir. Verilerin temel amacı, etkinlikleri veya durumları kaydetmek, gerçek resmi veya gerçek olayı yakalamaya çalışmaktır. Bu tanımı destekleyen çalışmalar incelendiğinde, Ackoff (1989, s. 170) veriyi nesnelerin, olayların ve çevrelerinin özelliklerini temsil eden semboller olarak tanımlamıştır. Hoppe, Seising, Nürnberger ve Wenzel (2011, s. 584) ise veriyi basit işaret ve sembol dizileri olarak açıklamıştır.

Dilimize; bilişim, malumat ve enformasyon olarak çevrilen "Information" kelimesinin tanımlamaları incelendiğinde, Anthony Liew'n (2007, s. 1) karar ve / veya eylem için ilgili anlam, çıkarım veya girdi içeren bir mesaj olarak açıladığı görülmektedir. Temel olarak bilişimin amacı karar vermeye, problemleri çözmeye veya bir firsatı gerçekleştirmeye yardımcı olmaktır (Hoppe vd., 2011, s. 584; Rowley, 2007, s. 166; Zins, 2007, s. 480-481). Bilişim, Bellinger, Castro ve Mills (2021, s. 2) tarafından ise "kim", "ne", "nerede" ve "ne zaman" sorularına yanıtlar sağlaması ve verinin yararlı hale gelmesi için işlenmesi durumu olarak tanımlanmıştır.

Bilginin (knowledge) ise bir kişinin zihninde depolanan, deneyim ve kişinin çevresiyle etkileşim yoluyla kazanılan insan uzmanllğı olduğu ifade edilmektedir (Brodie ve Brodie, 2009, s. 138). Bilgi; zihinde veya beyinde bulunan biliş veya tanıma (know-what), eyleme geçme (know-how) ve anlama (know-why) anlamına gelmektedir. Bu bağlamda, bilginin amacı hayatı iyileştirmektir. İş bağlamında ise bilginin amacı, işletme ve tüm paydaşları için değer yaratmak veya arttırmaktır (Liew, 2007, s. 2).

Bu açıdan, yönetim bilişim sistemlerini, yönetim bilgi sistemleri olarak kavramsallaştırmak daha doğru bir yaklaşım olacaktır. YBS'nin gelişim sürecinde önce bilgi üzerine yoğunlaştığ yakın dönemde ise teknoloji/örgütsel ve yönetim/sosyal odağa geçiş izlediği ifade edilmektedir (Alan, 2019, s. 78). Palvia, Salam ve Soliman (2003, s. 289), genç ve özgün bir disiplin olarak kabul edilen YBS'nin dünya çapında sürekli gelişmekte ve kendini yenilemekte olduğunu ifade etmektedir. Bilişim teknolojilerinin ve ilgili uygulamaların değişim hızı, araştırmacıların belirli bir fenomene derinlemesine odaklanarak teori üretmesini ve YBS disiplininin olgunluğa erişmesini kısmen engellediği literatürde ifade edilen bir görüştür (Alma, Koç ve Coşkun, 2017, s. 2). Bu bağlamda, üniversitelerimizde yapılan bilimsel faaliyetlerin uluslararası literatüre uygun bir biçimde gelişmesi önemlidir. Bilimsel faaliyetlerin öncelikleri güncel trendler, gelişmeye açık alanlar, akademiye ve uygulamacılara nitelikli bilgi üretecek konular olmalıdır. $\mathrm{Bu}$ açıdan, üretilen çıktılardan tezlerin akademik uzmanlık ve nitelikli insan gücü yetiştirmedeki önemi büyüktür. Geleceğin bilim insanlarını yetiştirme misyonuyla tasarlanan "YÖK-Gelecek Projesi", ülkemiz için öncelikli alanlarda nitelikli öğretim elemanı yetiştirmeyi hedeflemektedir. Ülkemizin kalkınma yolundaki ihtiyaçlarına paralel olarak kritik teknoloji alanlarından bazıları bilgi güvenliği, büyük veri ve büyük veri analitiği, geniş bant teknolojileri, nesnelerin interneti, yapay zeka ve makine ögrenmesi, bulut bilişim ve modelleme ve simülasyon teknolojileridir (Yükseköğretim Kurulu [YÖK], 2020). Belirlenen kritik teknolojiler genellikle bilgisayar bilimleri ve karar bilimleri disiplinlerinde çalssılan konular olmakla 
birlikte, bu disiplinlerden referans disiplin olarak yararlanan YBS disiplininin de araştırmalarına rehberlik etmekte ve disiplinlerin çalıştı̆̆ konular büyük ölçüde benzerlik göstermektedir.

$\mathrm{Bu}$ araştırmada, YBS'nin diğer disiplinlere göre dinamik ve hızlı gelişim gösteren yapısı dikkate alınarak, bu alanda tamamlanan lisansüstü tezler analiz edilmiştir. Söz konusu sahada çalışlan konuların irdelenmesi, geçmiş ve güncel durumun karşılaştırılması, uluslararası literatürle ve ulusal politikaların hedefleriyle karşılaştırılmasının önemli olduğu düşünülmektedir. Araştırma sonuçlarının karar vericilerin üretecekleri stratejilerin şekillenmesi ve mevcut politikalarla ilişkilendirilmesi bakımından da katkı sağlayacağı düşünülmektedir.

\section{Literatür Taraması}

YBS'nin bir disiplin olarak ifade edildiği ilk günden bu yana hangi disiplinlerden etkilendiği, YBS disiplini kapsamında geliştirilen teoriler, YBS araştırmalarındaki bağımlı değissken nedir sorunsalı ve disiplin altında var olan konu çeşitliliğinin YBS’nin geleceği için yararlı $\mathrm{m} ı$ yoksa zararlı $\mathrm{m}$ olduğu süregelen bir tartısmadır (Keen, 1980, s. 9; Landry ve Banville, 1992, s. 77). Keen (1980, s. 9); bilgisayar kullanımının önemli fakat nasıl kullanılacağı bilgisinin sınırlı olduğu yıllarda YBS tanımını, "davranışsal, yönetimsel ve teknik konuların bir birleşimi” olarak ifade etmektedir. MIT’nin Bilişim Sistemleri Araştırma Merkezi’nde lisansüstü çalışmalar için genel araştırma başlığını "organizasyonlarda bilişim sistemlerinin etkin bir biçimde tasarımı, dağıtımı ve kullanımı" şeklinde ifade ettiklerini belirtmektedir. Bu başlıktaki etkinliğin ölçülmesinin ve organizasyon kavramlarının kilit öneme sahip olduğu vurgulanmakta ve bilgisayar bilimleri dışında kalan söz konusu konuların bilgi ekonomisi, sosyal psikoloji, performans ölçümü ve yönetim bilimleriyle ilişkisinin bu kapsamdaki disiplinlere referans gösterilmesi gerektiğinin altı çizilmektedir. Keen (1980, s. 13), YBS disiplini altında teorilerin oluşması için belirli sınırlar içinde disiplinin daha tutarlı hale getirilmesi ve kümülatif bir araştırma geleneğinin oluşması gerektiğini belirtmektedir. Alavi, Carlson ve Brooke (1989, s. 363), Keen'in (1980, s. 13) ifade ettiği görüşler çerçevesinde bir araştırma tasarlayarak 1968-1988 yılları arasında YBS alanında yazılan 792 makaleyi incelemiştir.

Tablo 1. Barki-Rivard-Talbot'm YBS Simflandirmast

\begin{tabular}{ll}
\hline Sınıflar & Kapsadığı Örnek Alanlar \\
\hline Referans Disiplinler & Davranış bilimleri, bilişim kuramı, yönetim bilimleri, bilgisayar bilimleri, iktisat bilimi \\
\hline Diş Çevre & Ekonomik çevre, yasal çevre, politik çevre ve sosyal çevre \\
\hline Teknolojik Çevre & Yazılım, donanım, bilgisayar ağları, işletim sistemleri, veri tabanı yönetim sistemi, \\
& programlama dilleri \\
\hline Örgütsel Çevre & $\begin{array}{l}\text { Örgüt özellikleri (büyüklük, vs.), örgüt fonksiyonları (pazarlama, vs.), görev özellikleri } \\
\text { (karmaşıklık) ve örgüt dinamiği (örgütsel değişim) }\end{array}$ \\
\hline Bilişim Sistemleri Yönetimi & Planlama (örneğin; kritik başarı faktörleri), örgütleme (örneğin; BS’de merkezileşme ve \\
& ademi merkeziyet), insan kaynakları (örneğin; veri yönetim ekibi), değerlendirme \\
& (örneğin; maliyet/fayda analizi) ve kontrol, donanım ve yazıllım kaynak yönetimi, veri \\
& kaynak yönetimi, BS güvenliği, BS yönetim sorunları (örneğin; teknoloji adaptasyon \\
& problemleri) \\
\hline Bilişim Sistemleri Gelişimi ve & Geliştirme stratejileri, yaşam döngüsü faaliyetleri (bilişim gereksinim analizi), test, \\
Operasyonlar & geliştirme yöntemleri ve araçları (veri akış diyagramları vs.), proje yönetimi, kullanıcı \\
& katılımı ve uygulama. Operasyonlar olarak ise veri doğrulama, işleme ve veritabanı \\
& faaliyetleri gibi örnekler. \\
\hline Bilişim Sistemleri Kullanımı & BS’nin örgüt içi kullanım, son kullanıcılar, BS destek türleri, BS erişim türleri ve BS \\
& işleme türleri (online, vs.) \\
\hline Bilişim Sistemleri & BS türleri (YBS, karar destek sistemleri, uzman sistemler, bilgisayar temelli iletiş̧im \\
& sistemleri, dokuman yönetim sistemleri, hareket işleme sistemleri, vb.), pazarlama \\
& bilişim sistemleri, sağlık bilişim sistemleri, insan kaynakları bilişim sistemleri, vb. \\
& Kullanıcı ara yüzü, grafik, bilgi tabanı. \\
\hline Bilişim Sistemlerinde Eğitim ve & BS araştırmalarında trendler, BS mevcut durumunu analiz eden araştırmalar, BS \\
Araştırma & araştırmalarının tarihsel yönleri, eğitim yönleri (BS müfredat programları) \\
\hline Kaynak: Barki vd. (1988, s. 305) &
\end{tabular}

Yürütülen çalışmada Barki, Rivard ve Talbot (1988, s. 299) tarafından YBS disiplinin çalışma alanını belirleyebilmek ve farklı bileşenleri tanımlamak için 1100 anahtar kelimeden oluşan bir sınıflandırma kullanılmıştır. Sınıflandırma Tablo 1'de görülmektedir. Alavi vd. (1989, s. 368) ayrıca her bir çalışmanın deneysel olup olmadığını inceleyerek ayrıntılı bir durum analizi çalışması yürütmüştür. Analiz sonuçlarına göre belirtilen tarih aralığındaki çalısmaların yarısından fazlasının deneysel olmayan bir yapıda olduğu ve tüm çalışmaların üçte birlik bölümünün ise YBS kavramları, modelleri ve nasıl uygulanacağını anlatan 
çalışmalardan oluştuğu ifade edilmektedir. En çok çalışmanın gerçekleştiği konu başlıkları ise sırasıyla; bilişim sistemleri yönetimi, bilişim sistemleri, bilişim sistemleri gelişimi ve operasyonlar, referans disiplinlerdir. Alavi vd. (1989, s. 369); teorilerin araştırma sürecine ve kullanılacak yöntemlere rehberlik ettiği düşünüldügünde 20 yıllık periyotta YBS temelli teorik makale sayısının sadece 15 olmasının endişe verici olduğunu ifade etmektedirler. Bu problemin ortadan kalkması için farklı araştırma yöntemlerinin kullanılması gerektiğini, bir diğer deyişle metodolojik çoğulculuğun gerekli olduğunun altını çizmektedirler. Metodolojik çoğulculuk YBS araştırmalanı için birden fazla paradigmanın disiplin içinde oluşmasına izin verecektir.

Benbasat ve Weber (1996, s. 389); YBS alanındaki çeşitliliği üç temel başlık altında incelemiştir. Bu başlıklardan ilki araştırma konularında ele alınan problemlerdeki çeşitlilik, ikincisi araştırmalara rehberlik eden teori ve referans disiplinlerdeki çeşitlilik üçüncüsü ise veri toplama, analiz ve yorumlama yöntemlerinde çeşitliliktir. 80'li yıllara göre 90'lı yılların daha fazla çeşitlilik sahibi olduğunu, alan araştırmacılarının uzmanlık seviyelerindeki gelişmenin teorik ve metodolojik açıdan çeşitlilik kalitesinin arttırdığını ve ilk günden bu yana YBS disiplini için referans disiplinler olarak ifade edilen bilgisayar bilimi (mühendislik ve tasarım araştırmaları için), yönetim ve bilişsel bilimler (karar süreci araştırmaları için), örgüt bilimi (sosyal süreç araştırmaları için) ve iktisata (ekonomik verimlilik ve iş süreçleri için) güvenin daha da arttığını ifade etmektedir. Benbasat ve Weber (1996, s. 397), YBS disiplini için çeşitliliğin faydalı olduğunu fakat bu disiplini diğerlerinden ayıran paradigma ve teorilerin muhakkak inşa edilmesi gerektiğinin altını çizmektedirler. Bu bağlamda, çeşitliliğin etkisinin seçilecek performans kriterlerine göre ampirik olarak ölçülmesinin önem arz ettiği Benbasat ve Weber (1996, s. 398) tarafindan vurgulanmaktadır.

Laudon ve Laudon, (2020, s. 28), bilişim sistemlerini teknik ve davranışsal yaklaşımlardan etkilenen sosyoteknik bir yapı olarak tanımlamaktadır. Bu yapı Şekil 1'de görülmektedir.

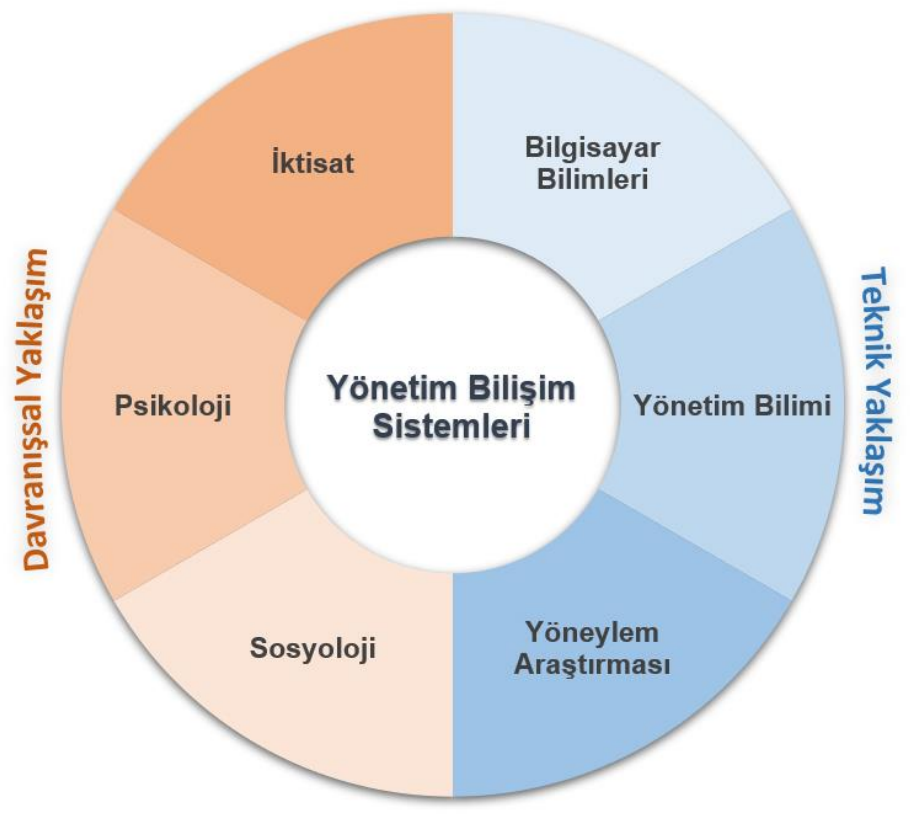

Şekil 1. Bilişim Sistemlerine Çağdas Yaklaşımlar (Laudon ve Laudon'den (2020, s. 28) uyarlanmısttr)

Bilgisayar bilimleri; hesaplanabilirlik teorileri, hesaplama yöntemleri, verimli veri depolama ve erişim yöntemlerini oluşturmakla ilgilenmektedir. Karar verme ve yönetim uygulamaları için model geliştirme görevi ise yönetim bilimi kapsamında değerlendirilmektedir. Nakliye, stok kontrol ve işlem maliyetlerinin optimize edilmesi için matematiksel tekniklere odaklanan alan ise yöneylem araştırmasıdır. Laudon ve Laudon (2020, s. 28) bu boyutları teknik yaklaşım olarak değerlendirmektedir. Laudon ve Laudon (2020, s. 29); davranışsal yaklaşımın ise bilişim sistemlerinin geliştirilmesi ve sürdürülebilmesi için teknik çözümlerden ziyade tutum, yönetim, örgütsel politika ve davranış değişikliklerine odaklanan sosyoloji, psikoloji ve iktisat alanları olduğunu ifade etmektedir.

Bir disiplinde temel gelişmeleri ve eğilimleri anlamak için mevcut durumun analiz edilmesi oldukça önemlidir. YBS genç bir disiplin olarak, alanında gerçekleşmiş çeşitli durum analizi araştırmalarına sahiptir ve bu araştırmalarda genellikle bibliyometrik yöntem kullanılmaktadır. Bibliyometrik; bilgi ve belge 
yönetimi alanında ortaya çıkan bir yöntem olarak yazar, bağlantı, atıf - ortak atıf, patentler ve yayınlar gibi bilgileri girdi olarak kullanarak stratejik karar verme sürecinde kullanılabilecek büyük miktardaki tarihsel verinin keşfedilmesi, düzenlenmesi ve gizli konuları belirlenmesi süreci olarak tanımlanmaktadır (Daim, Rueda, Martin ve Gerdsri, 2006, s. 983; La Paz, Merigó, Powell, Ramaprasad ve Syn 2020, s. 433; Rueda, Gerdsri ve Kocaoglu, 2007, s. 2905).

Örneğin; Abedin, Jafarzadeh ve Olszak (2020, s. 1) Information Systems Management dergisinde 1984-2019 yılları arasında yayınlanan 1411 makaleyi bibliyometrik yöntem ile incelemiştir. Makalelerin aldığ1 atıflar, yıllara göre dağılımları, en çok atıf alan makaleler ve yazarları çalışma kapsamında incelenmiştir. Anahtar kelimeler dikkate alınarak yapılan grafiksel analizlerde 1996-2007 yılları arasında bilişim yönetimi, proje yönetimi, karar verme, bilgi yönetimi ve elektronik ticaret kelimelerinin 2008-2019 yllları arasında da popüler olduğu ifade edilmektedir. İnovasyon, malzeme ihtiyaç planlama, sosyal medya ve bilişim teknolojileri yönetimi gibi yeni kavramların ise ikinci dönemde ortaya çıan yeni sözcükler olduğu çalışma kapsamında belirtilmiştir. 1996-2019 yılları arasında çalışılan konu başlıkları çalışma sayısı açısından Tablo 2'de görülmektedir.

Tablo 2. 1996-2019 Yillar Arasinda "Information Systems Management" Dergisinde Yayzmlanan Makalelerin Konu Dăgllami ve En Sik Kullanulan Anabtar Kelimeler

\begin{tabular}{|c|c|c|}
\hline Konu & En Sik Kullanılan Anahtar Kelimeler & Çalışma Sayısı \\
\hline $\begin{array}{l}\text { Bilişim Sistemleri Kullanımı ve } \\
\text { Yönetim }\end{array}$ & $\begin{array}{l}\text { Yönetim Bilişim Sistemleri, Bilişim Yönetimi, Malzeme } \\
\text { İhtiyaç Planlama, Yazılım, Donanım, Dış Kaynak Kullanımı, } \\
\text { Teknoloji Kabulü }\end{array}$ & 1190 \\
\hline Örgüt Yönetimi ve Performans & $\begin{array}{l}\text { Örgütler, Stratejik Planlama, Proje Yönetimi, İKY, } \\
\text { Performans, Değișim Yönetimi }\end{array}$ & 485 \\
\hline e-Ticaret & Ticaret, Satış, Rekabet, Maliyet, Web Sayfası, Internet & 272 \\
\hline Bilişim Sistemi ve İnsan Davranışı & $\begin{array}{l}\text { Toplumlar ve Kurumlar, Güven, Davranışsal Araştırma, } \\
\text { İnsan Bilgisayar Etkileșimi, Sosyal Etkiler, Sosyal Yönler }\end{array}$ & 230 \\
\hline Araştırma Yöntemleri & $\begin{array}{l}\text { Anket, Matematiksel Modelleme, Örnek Olay, Simülasyon, } \\
\text { Yapısal Eşitlik Modeli, Regresyon }\end{array}$ & 125 \\
\hline Karar Verme ve Bilgi Yönetimi & $\begin{array}{l}\text { Karar Destek Sistemleri, Problem Çözme, Bilgi Yönetimi } \\
\text { Sistemleri }\end{array}$ & 110 \\
\hline Alana Özel Bilişim Sistemleri & $\begin{array}{l}\text { Sağlık, Finans, Eğitim, Tedarik Zinciri Yönetimi, Coğrafi Bilgi } \\
\text { Sistemleri }\end{array}$ & 98 \\
\hline Yapay Zeka ve Veri Analizi & $\begin{array}{l}\text { Yapay Zeka, Veri Madenciliği, Bilgi Edinme, Büyük Veri, } \\
\text { Rekabetçi Zeka, Öğrenme Sistemi }\end{array}$ & 66 \\
\hline Bilişim Sistemlerinde Güvenlik & Risk Yönetimi, Veri Güvenliği, Bilgisayar Suçları & 51 \\
\hline Sosyal Medya & Çevrimiçi Sosyal Ağ, Çevrimiçi Topluluklar, Sanal Gerçeklik & 21 \\
\hline
\end{tabular}

Kaynak : Abedin vd. (2020, s.8)

Beydoun, Abedin, Merigó ve Vera (2019, s.491), Information Systems Frontiers dergisinde 1999-2018 yılları arasında yayınlanan 855 makaleyi dikkate alarak gerçekleştirdiği bibliyometrik analiz sonucuna göre ise 20 yıllık dönemde 10 farklı konu başlı̆ının çalışıldığını ifade etmektedir. Bu konu başlıkları Tablo 3'te görülmektedir.

Tablo 3. 1999-2018 Yillar Arasinda Information Systems Frontiers Dergisinde Yaymlanan Makalelerin Konu Dă̆lımı

\begin{tabular}{lc}
\hline Konu & Çalışma Sayıs \\
\hline Bilişim Teknoloji Tabanlı Hizmetler & 136 \\
\hline Faaliyet Yönetimi & 93 \\
\hline Bilgi Yönetimi & 80 \\
\hline Kurumsal Bilişim ve Mimari & 80 \\
\hline Analitik & 76 \\
\hline Bilişim Sistemlerinde Araştırma Yöntemleri ve Teoriler & 74 \\
\hline Bilişim Sistemleri Risk Yönetimi & 65 \\
\hline Nesnelerin İnterneti ve Ulaşılabilir Bilişim & 60 \\
\hline Bilişim Sistemleri Kullanımı & 58 \\
\hline İnternetin Geleceği & 43 \\
\hline Kaynak : (Beydoun vd., 2019, s.491)
\end{tabular}


2003-2012 yılları arası popüler anahtar kelimelerin bilgi yönetimi, bilişim paylaşımı ve iş süreçleri yönetimi olduğu belirtilmektedir. Açık veri, iş zekası, sosyal medya ve nesnelerin interneti anahtar kelimelerinin ise özellikle 2013 yllından itibaren modern teknolojilerle birlikte daha sık görüldüğü araştırma kapsamında ifade edilmektedir.

Jeyaraj ve Zadeh, (2020, s. 15) sadece anahtar kelimeleri kullanarak 6 farklı bilişim sistemleri dergisini 2003-2017 yılları arasını dikkate alarak konu modellemesi yöntemiyle analiz etmiştir. European Journal of Information Systems (EJIS), Information Systems Journal (ISJ), Information Systems Research (ISR), Journal of Management Information Systems (JMIS), Journal of the Association for Information Systems (JAIS), and MIS Quarterly (MISQ) dergilerinden toplam 2962 makale analiz kapsamında ele alınarak 50 çalışma konusu oluşturulmuştur. 1502 makaleyi dikkate alan ilk 13 konu Tablo 4'te görülmektedir.

Tablo 4. 2003-2017 Yulları arasinda 6 farkì Bilisim Sistemleri Dergisinde Yaymlanan Makalelerin Konu Dăğllmı ve Sik Kullamlan Anabtar Kelimeler

\begin{tabular}{|c|c|c|}
\hline Konu & Anahtar Kelimeler & Çalışma Sayısı \\
\hline $\begin{array}{l}\text { Bilişim Sistemleri } \\
\text { Uygulamaları }\end{array}$ & $\begin{array}{l}\text { BS uygulaması, örnek olay incelemesi, kurumsal kaynak planlama, kurumsal sistemler, } \\
\text { BS başarıs }\end{array}$ & 203 \\
\hline $\begin{array}{l}\text { Bilişim Teknolojileri } \\
\text { Adaptasyonu }\end{array}$ & BT adaptasyonu, BT yayllmm, BT'de inovasyon, TAM, dijital uçurum & 179 \\
\hline $\begin{array}{l}\text { Bilişim Sistemleri } \\
\text { Geliştirme }\end{array}$ & BS gelistirme, proje yönetimi, açık kaynak kodlu yazıllm, BT İnovasyon, kontrol & 166 \\
\hline $\begin{array}{l}\text { Bilişim Teknolojilerinin } \\
\text { Katma Değeri }\end{array}$ & $\begin{array}{l}\text { BT'nin katma değeri, BT yatırmı, verimlilik, } \\
\text { BT ekonomisi, isletme performans }\end{array}$ & 164 \\
\hline Araştırma Yöntemleri & $\begin{array}{l}\text { Araștorma yöntemleri, belirli bir temele dayanan teori, BS araștırma, eylem araștormasi, } \\
\text { tasarm bilimi (design science) }\end{array}$ & 163 \\
\hline e-Ticaret & e-Ticaret, elektronik pazar, BS ekonomisi, oyun teorisi, tüketici davranşlar & 160 \\
\hline Sosyal Medya & 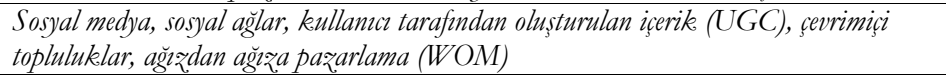 & 158 \\
\hline $\begin{array}{l}\text { Bilişim Sistemleri } \\
\text { Kullanımı }\end{array}$ & $\begin{array}{l}\text { BS Kullanmm, teknoloji kabulï, performans, Teknoloji kabul modeli (TAM), BS } \\
\text { basarnst }\end{array}$ & 157 \\
\hline Çevrimiçi Güvenlik & Güven, sanal ekipler, mabremiyet, is birliği, teknoloji kabulü & 155 \\
\hline $\begin{array}{l}\text { Bilişim Teknolojileri } \\
\text { Kabiliyeti }\end{array}$ & $\begin{array}{l}\text { BT Kabiliyetleri, işletme performansı, kaynak tabanlı yaklașım, dinamik kabiliyetler, } \\
\text { örnek olay }\end{array}$ & 150 \\
\hline Bilgi Yönetimi & Bilgi yönetimi, bilgi paylassımı, bilgi yönetim sistemleri, eylem arastırması, sanal ekipler & 139 \\
\hline $\begin{array}{l}\text { Bilişim Teknolojilerinde } \\
\text { Dış Kaynak Kullanımı }\end{array}$ & Dış kaynak. kullammı, işlem maliyeti ekonomisi, offshore, BT yönetimi, vekalet teorisi & 104 \\
\hline $\begin{array}{l}\text { Bilişim Sistemlerinde } \\
\text { Güvenlik }\end{array}$ & BS güvenlï̈i, mabremiyet, BS ekonomisi, uygunluk, koruma motivasyonu teorisi & 91 \\
\hline
\end{tabular}

Araştırmada, 2010-2017 yılları arasında bilişim sistemlerinde güvenlik, sosyal medya ve çevrimiçi güvenlik konularının yükseliş eğiliminde olduğu ifade edilmektedir. Bilişim sistemleri geliştirme, bilişim teknolojileri adaptasyonu ve bilişim sistemleri kullanımı konularının ise dergi yılı ve türünden bağımsız olarak temel konular olduğu belirtilmektedir.

Coşkun, Özdağoğlu, Damar, Çallı (2019, s. 181) bilgi sistemleri disipliniyle ilgili 2008 ve 2019 ylları arasında yayımlanan Web of Science makalelerini analiz ettiği çalısmalarında zaman aralığını iki bölüme ayrılarak, 2008-2013 ve 2014-2019 dönemlerinde geçmiş ve güncel olan konu trendlerini karşılaştırmıştır. Anahtar kelime kümelerine göre ilk dönemde kriptoloji, güvenlik, sensörler ve ağlar, yapay zeka, veri madenciliği, web hizmetleri, kurumsal sistemler ve metin madenciliği sıklıkla çalışlan konulardır. İkinci dönemde ise yeşil bilişim, enerji verimliliği, nesnelerin interneti, büyük veri, yapay zeka, sensörler, güvenlik, makine öğrenmesi, öznitelik seçimi ve bulut bilişim öne çıkan konular olmuştur. Anahtar kelimeler bakımından son dönemlerde en s1k tekrarlandığ1 gözlemlenen kelimeler mahremiyet, IOT, kimlik doğrulama, güvenlik, kablosuz sensör ağları, bulut bilişim, makine öğrenimi, enerji verimliliği, sosyal medya, ontoloji, algoritmalar ve kümelemedir.

Alma vd. (2017, s. 5) çalışmalarında Türkiye'de Yönetim Bilișim Sistemleri disipliniyle ilişkili olan 380 makaleyi içerik analizi yöntemini kullanarak incelemişlerdir. 1999 ve 2016 y1lları arasında yayımlanan bu makaleler; odaklandıkları temel konu, yöntem, veri kaynakları ve yazarların bölümleri bakımından incelenmiştir. Tematik yapının oluşturulması sürecine Laudon ve Laudon'ın 2003 yllından yayınlanan YBS kitabında yer alan konu başlıkları ve içerdikleri alt-başııklar rehberlik etmiştir. Bu bağlamda, çalışmaların konulara göre dağılımları Tablo 5’te görülmektedir. 
Tablo 5. 1999 ve 2016 Taribleri Arasında Yaymlanan Makalelerin Konu Dăğlımı

\begin{tabular}{|c|c|}
\hline Konu & Çalışma Sayısı \\
\hline Bilișim Sistemleri ve İșletmeler & 80 \\
\hline Karar Vermeyi Geliştirme & 43 \\
\hline Bilişim Sistemleri, Organizasyonlar ve Strateji & 40 \\
\hline Bilgi Yönetimi & 36 \\
\hline Kurumsal Sistemler: Kurumsal Kaynak Planlama, Müșteri İlișkileri Yönetimi, Tedarik Zinciri Yönetimi & 27 \\
\hline Veri Kaynaklarını Yönetmek ve Veritabanı & 26 \\
\hline Diğer & 20 \\
\hline Dijital Firmayı Yönetmek & 20 \\
\hline E-ticaret ve E-iş & 17 \\
\hline Bilişim Sistemlerinin Güvenliği & 14 \\
\hline Bilişim Sistemlerinde Etik ve Sosyal Sorunlar & 14 \\
\hline Proje Yönetimi & 12 \\
\hline Bilişimde Güncel Konular & 7 \\
\hline Bilgi Teknolojileri Altyapis1 & 6 \\
\hline Telekomünikasyon ve Ağlar & 6 \\
\hline Bilişim Sistemleri Tasarımı ve Geliştirme & 6 \\
\hline Yönetim Bilişim Sistemleri Araştırmaları & 6 \\
\hline Küresel Sistemleri Yönetmek & 0 \\
\hline
\end{tabular}

Kaynak: Alma vd. (2017, s. 5-6)

Çalışmada bilişim sistemleri ve işletmeler konu başlı̆̆ı altında değerlendirilen e-devlet çalışmalarının özellikle 2008 ve 2013 y1lları arsındaki yoğunluğu dikkati çekmektedir. Çalışmada güncel konular olarak nitelendirilen büyük veri, makine öğrenmesi, açık kaynak kodlu yazılım, yeşil bilişim ve yapay zeka kavramlarının oldukça sınırlı sayıda çalışma tarafından incelendiği görülmektedir. Ayrıca, sistem analizi ve geliştirme konulu çalışmaların az sayıda olması dikkat çekmektedir. Yönetim bilişim sistemleri araştırmaları olarak tanımlanan konu kapsamında yürütülen araştırmalar da azınlıktadır.

Türkiye'de, YBS anabilim dalında tamamlanmış lisansüstü tez çalışmalarını dikkate alan araştırmaların da bibliyometrik ve içerik analiz yöntemlerinden yararlandığ1 görülmektedir. İçerik analizi bibliyometrik yaklaşımdan farklı olarak güçlü bir veri azaltma yöntemi olarak çok sayıda dokümanı az sayıda kategori başlığ1 altında sınıflandırabilecek bir kalitatif yöntem olarak ifade edilmektedir (Stemler, 2001, s. 2).

Yarlikas (2015, s. 142), 125 tezi içerik analizi yöntemiyle incelemiş ve "bilişim sistemlerinde karar verme" konulu tezlerin daha çok sayıda olduğunu saptamıştır. Bu araştırmaya göre, literatür analizi ve anket yöntemiyle veri toplayarak istatistiksel analiz, tezlerde en çok kullanılan yöntemlerdir. Araştırma sonucunda, lisansüstü tezlerin 22 farklı konu başlığ1 altında yürütüldüğ̈̈ ifade edilmektedir.

Özköse (2017, s. 101), 2006-2016 yılları arasında tamamlanan 152 tezin İngilizce özetlerini incelediği çalışmasında, en sık kullanılan 250 kelimeden oluşan 6 konulu Bibliyometrik haritalama oluşturmuştur. Bu konular sırasılla; uzaktan eğitim, veri madenciliği, eğitim, üretim süreci, bilişim sistemleri (e-Ticaret ve bulut bilişim), kullanılabilirlik ve istatiksel analizler olarak ifade edilmektedir. YBS anabilim dalında eğitim başlığ1 altında yürütülen çalışmaların dünya ölçeğine göre çok daha yoğun işlendiği araştırma bulgularında verilmektedir. Aytaç (2020, s. 53), içerik analizi yöntemiyle 2015-2020 y1lları arasında tamamlanan 356 tezi incelediği çalışmasında, tez konuların yoğun olarak yazılım, bilişim sistemlerinde karar verme ve bilişim sistemleri üzerine odaklı olduğunu belirtmiştir. Alt konuların ise makine öğrenmesi, bulut bilişim, büyük veri, blok zincirinden oluştuğu ve tezlerde ağırlıklı olarak anket yönteminin kullanıldı̆̆1 sonucuna ulaşmiştır.

Türkiye'de YBS alanında düzenlenen konferans bildirileri üzerine yürütülen çalışmada ise bilgi yönetimi, teknoloji yönetimi, yenilikçilik, kurumsal kaynak planlaması gibi sosyal konuların öncelikli olarak çalışıldığ1 görülmektedir (Özkoç, 2019, s. 35). Bu konuları takip eden başlikların ise sırasıyla veri madenciliği, yapay zeka ve makine öğrenmesi, bilgi sistemleri (teknik konular), elektronik uygulama konuları, iş zekası - karar destek sistemleri, sosyal ve dijital medya, bilgi güvenliği ve bilişim hukuku, yeni trendler, internet teknolojileri, mikro denetleyiciler ve uygulamalar, coğrafi bilgi sistemleri olduğuna çalışmada yer verilmiştir.

Keşifsel olan bu araştırmada, Türkiye'de YBS alanında tamamlanan lisansüstü tezlerin Gizli Dirichlet Ayrımı yöntemiyle konu modellemesini oluşturarak görece yeni bir disiplin olan YBS’nin; 
1. Hangi yan disiplinlerden etkilendiği?

2. Hangi konulara odaklandığı?

temel araştırma soruları olarak belirlenmiştir.

\section{Gizli Dirichlet Ayrımı (GDA) Algoritması}

Konu modellemesi, büyük hacimli verilerin az sayıda konu başlığına indirgenmesi ve gizli başlıkların keşfedilmesi için kullanılan bir yöntem olarak tanımlanmaktadır (Kherwa ve Bansal, 2018, s. 2). GDA (LDA - Latent Dirichlet Allocation), farklı disiplinlerde kullanılan bir konu modellemesi yöntemidir ve çok sayıda belgeyi kelimelere göre özetleyerek bu belgelerin belirli başlıklar altında değerlendirilmesini sağlayan bir olas1lık modelidir (Blei, $\mathrm{Ng}$ ve Jordan, 2003, s. 993). LDA yönteminde modellenecek olan veri kümesi külliyat (corpus), külliyat içindeki her bir öğe doküman (document), doküman içindeki her bir kelime ise terim (term) olarak adlandırılır. GDA yönteminin amacı ise, külliyatın kapsamlı bir temsilini gizli içeriklerle ortaya çıkararak belirlenen sayıdaki konular (topics) altında özetlemektedir. GDA yöntemi sonuçlarının yorumlanması için kelime-konu $(\phi)$ ve doküman-konu $(\theta)$ olmak üzere iki matristen yararlanılmaktadır. Kelime-konu matrisinin K (konu sayısı) ve V (külliyattaki kelimeler), doküman-konu matrisinin ise K (konu sayısı) ve D (külliyattaki dokümanlar) boyutları bulunmaktadır. (Maier vd., 2018, s. 94). Bu süreç Şekil 2'de görülmektedir.

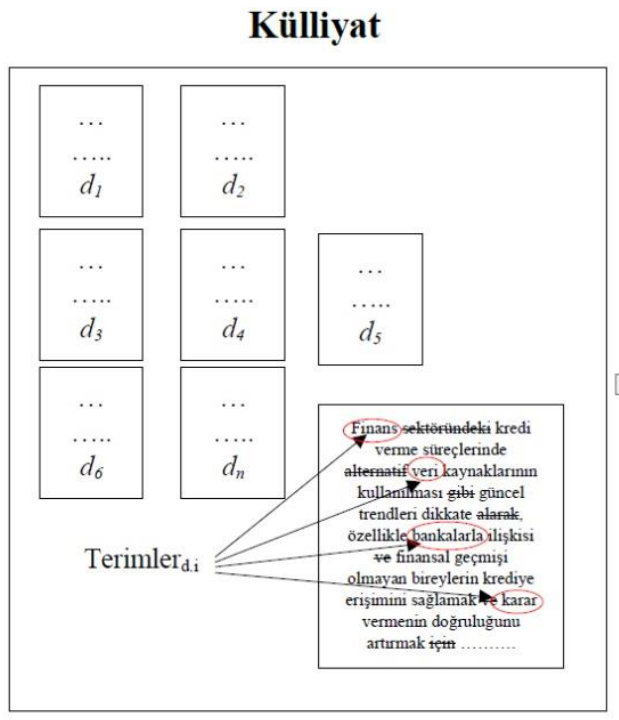

Algoritma

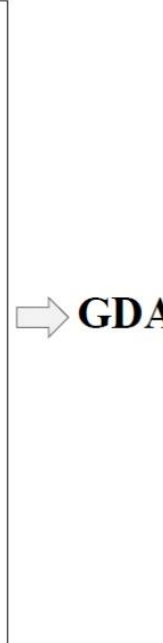

\section{Sonuçlar}

\begin{tabular}{|l|c|c|c|c|}
\hline V & Konu $_{1}$ & Konu $_{\boldsymbol{1}}$ & $\ldots$ & $\boldsymbol{K o n u}_{\boldsymbol{k}}$ \\
\hline Finans & 0.18 & 0.01 & $\ldots$ & 0.09 \\
\hline Veri & 0.02 & 0.12 & $\ldots$ & 0.07 \\
\hline Banka & 0.06 & 0.05 & $\ldots$ & 0.12 \\
\hline Karar & 0.01 & 0.06 & $\ldots$ & 0.09 \\
\hline Kredi & 0.09 & 0.02 & $\ldots$ & 0.07 \\
\hline$\ldots$ & $\ldots$ & $\ldots$ & $\ldots$ & $\ldots$ \\
\hline
\end{tabular}

\begin{tabular}{|l|l|l|l|l|}
\hline$D$ & Konu $_{1}$ & Konu $_{1}$ & $\ldots$ & Konu $_{k}$ \\
\hline$d_{1}$ & 0.08 & 0.01 & $\ldots$ & 0.09 \\
\hline$d_{2}$ & 0.02 & 0.12 & $\ldots$ & 0.07 \\
\hline$d_{3}$ & 0.06 & 0.05 & $\ldots$ & 0.12 \\
\hline$d_{4}$ & 0.01 & 0.06 & $\ldots$ & 0.09 \\
\hline$d_{5}$ & 0.05 & 0.02 & $\ldots$ & 0.07 \\
\hline$\ldots$ & $\ldots$ & $\ldots$ & $\ldots$ & $\ldots$ \\
\hline$d_{D}$ & 0.08 & 0.01 & $\ldots$ & 0.09 \\
\hline
\end{tabular}

Maier vd (2018)' den uyarlanmıstor.

Şekil 2. GDA Algoritması

GDA yönteminde konular kelime olasılıklarına göre temsil edilmektedir, her bir kelime birden fazla konu içinde yer alabilir ve her bir konu altında en yüksek olasıllk değerine sahip kelimeler konu hakkında genel fikir vermektedir (Jelodar vd., 2019, s. 15171). GDA yönteminin, terim frekans1 - ters doküman frekansı (TF-IDF), gizli anlamsal analiz (LSA) ve olasılıklı gizli anlamsal analiz (PLSA) yöntemlerine göre daha üstün genelleme yeteneği (Bastani, Namavari ve Shaffer, 2019, s. 257) bu araştırmada tercih edilmesinin nedenidir. Araştırmada, Rapidminer yazıllımında bulunan ve Mallet altyapısını kullanan LDA operatöründen yararlanılmıstır (McCallum, 2018, s. 1).

\section{Yöntem}

\section{Verilerin Toplama Yöntemi}

Bu çalışmada, Türkiye'de YBS anabilim dalı ve bilim dalı kapsamında tamamlanan lisansüstü tezlerin metin madenciliği yöntemiyle konulara ayrılması amaçlanmaktadır. Araştırmada analiz edilecek veri kaynağını http://tez.yok.gov.tr/ adresinde listelenen tezler oluşturmaktadır. 534 yüksek lisans, 40 doktora tezi olmak üzere toplam 574 tez analiz kapsamında değerlendirilmiştir.

\section{Tanımlayıcı İstatistik}

Analiz kapsamında YBS anabilim dalında tamamlanmıs 503 tez, YBS bilim dalında ise tamamlanmış 71 tez değerlendirilmiştir. Tez türlerinin üniversitelere göre dağılımı Tablo 6’da görülmektedir. 
Tablo 6. Lisansüstü Tez̨lerin Üniversitelere Göre Tez. Tür Dağllamı

\begin{tabular}{lccc}
\hline Üniversite & Doktora & Yüksek Lisans & Toplam \\
\hline Toplam & 40 & 534 & 574 \\
\hline Gazi Üniversitesi & 21 & 68 & 89 \\
\hline Atatürk Üniversitesi & 11 & 25 & 36 \\
\hline Boğaziçi Üniversitesi & 4 & 124 & 128 \\
\hline Sakarya Üniversitesi & 3 & 25 & 28 \\
\hline Kadir Has Üniversitesi & 1 & 24 & 25 \\
\hline Yeditepe Üniversitesi & 29 & 29 \\
\hline Ufuk Üniversitesi & 18 & 18 \\
\hline Sivas Cumhuriyet Üniversitesi & 10 & 10 \\
\hline Osmaniye Korkut Ata Üniversitesi & 17 & 17 \\
\hline Karamanoğlu Mehmetbey Üniversitesi & 1 & 1 \\
\hline Haliç Üniversitesi & 29 & 29 \\
\hline Düzce Üniversitesi & 8 & 8 \\
\hline Dokuz Eylül Üniversitesi & 50 & 50 \\
\hline Cumhuriyet Üniversitesi & 4 & 4 \\
\hline Burdur Mehmet Akif Ersoy Üniversitesi & 9 & 9 \\
\hline Beykent Üniversitesi & 32 & 32 \\
\hline Başkent Üniversitesi & 21 & 21 \\
\hline Ankara Yildırım Beyazıt Üniversitesi & 12 & 12 \\
\hline Aksaray Üniversitesi & 18 & 18 \\
\hline Akdeniz Üniversitesi & 1 & 1 \\
\hline Adana Bilim ve Teknoloji Üniversitesi & 7 & 7 \\
\hline Adana Alparslan Türkeş Bilim ve Teknoloji Üniversitesi & 2 & 2 \\
\hline
\end{tabular}

YBS alanında tamamlanan tezlerin enstitülere göre dağılımı ve bilim dalı olarak bağı olduğu anabilim dalları Tablo 7'de görülmektedir.

Tablo 7. Lisansïstü Tęlerin Enstitü ve Anabilim Dallarna Göre Dağgllm

\begin{tabular}{|c|c|c|c|c|c|c|}
\hline Anabilim Dalı & $\overline{B E}$ & FBE & $\overline{\mathbf{I}} \mathbf{E}$ & LEE & SBE & Toplam \\
\hline Toplam & 89 & 49 & 18 & 5 & 413 & 574 \\
\hline Yönetim Bilișim Sistemleri Anabilim Dalı & 89 & 25 & 18 & 5 & 366 & 503 \\
\hline Yönetim Bilişim Sistemleri Bilim Dalı & & & & & 2 & 2 \\
\hline Sosyal Bilimler Anabilim Dalı & & & & & 1 & 1 \\
\hline İşletme Yönetimi Anabilim Dalı & & & & & 29 & 29 \\
\hline İşletme Anabilim Dalı & & & & & 5 & 5 \\
\hline Bilişim Sistemleri Bölümü & & & & & 10 & 10 \\
\hline Bilgisayar Mühendisliği Bölümü & & 3 & & & & 3 \\
\hline Bilgisayar Mühendisliği Anabilim Dalı & & 19 & & & & 19 \\
\hline Bilgisayar Bilimleri ve Mühendisliği Anabilim Dalı & & 2 & & & & 2 \\
\hline
\end{tabular}

BE: Bilişim Enstitüsü

FBE: Fen Bilimleri Enstitüsü

İE: İşletme Enstitüsü

LEE: Lisansüstü Eğitim Enstitüsü

SBE: Sosyal Bilimler Enstitüsü

YBS alanında tamamlanan tezlerin yıllara göre dağılımı Şekil 3'te görülmektedir. Özellikle 2016 yllından sonra yükseliş gösteren trendin 2020 yllında düşüş göstermesinin nedeni bu yllda tamamlanmış tezlerin tamamının araştırmanın yürütüldüğü Ocak 2021 döneminde henüz tez.yok.gov.tr veri tabanında yer almamasından kaynaklandığı düşünülmektedir. 


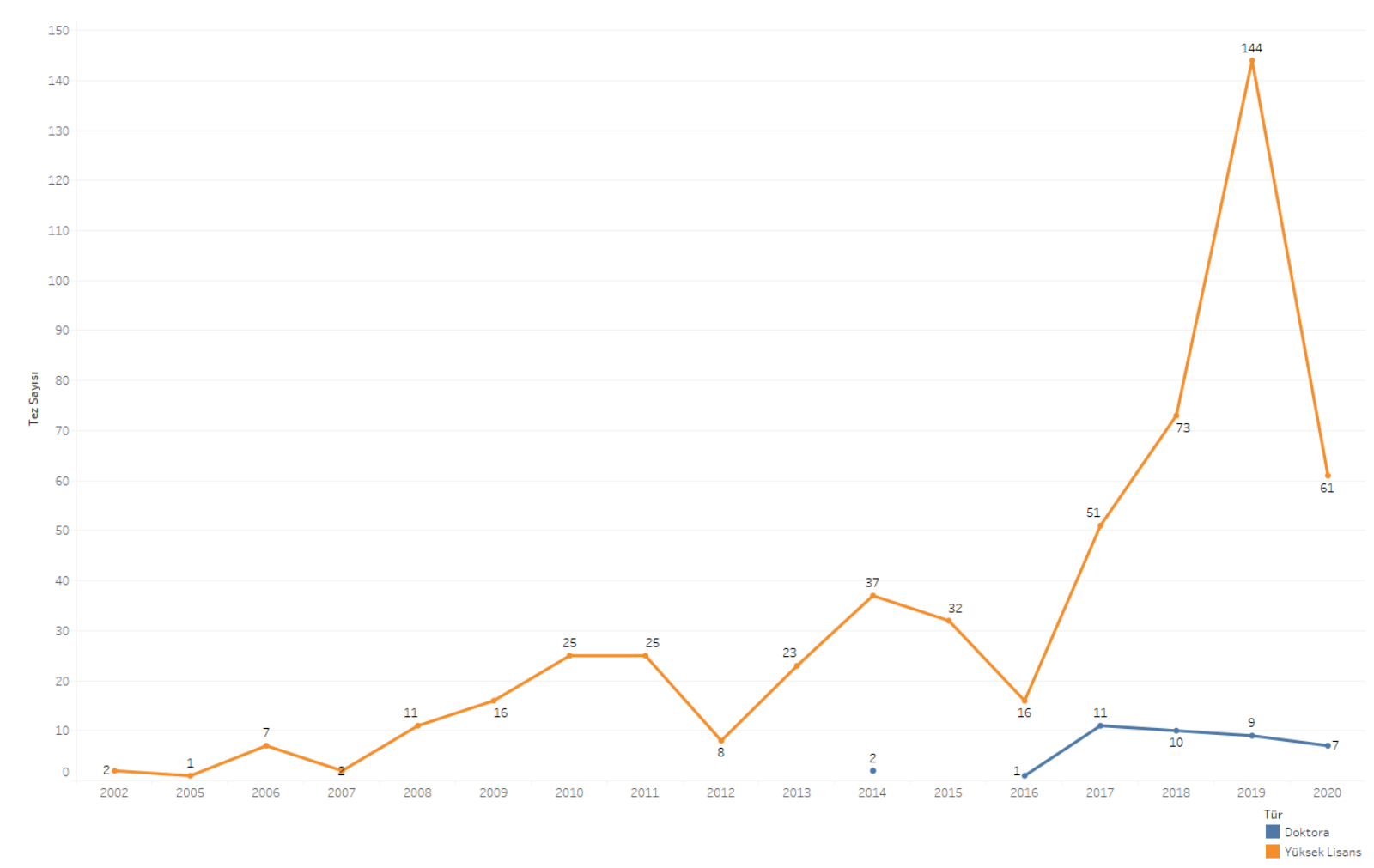

Şekil 3. Lisansïstü Tęleri Yıllara Göre Dağglımı

Analiz

\section{Metin Ön İşleme}

Özetlerin GDA yöntemi için hazırlanması ve gizli konu başlıklarının belirlenmesi için ön işlemdeki ilk aşama her bir özetin kelimelere ayrıştırılmasıdır. Bu aşamada ayrıca özetlerin içinde bulunan harf ve sayı harici tüm karakterlerin temizlenme işlemi yapılmıştır. İkinci aşamada her kelime küçük harfe dönüştürülmüş ve benzer kelimelerin aynı grupta toplanması sağlanmıştır. Üçüncü aşamada bilgi içermeyen edat ve bağlaçlar filtre edilmiştir. Bu aşamada ayrıca sık kullanılan ve araştırma için anlam ifade etmediği düşünülen kelimeler de filtrelenerek 200 kelimelik bir liste oluşturulmuştur. Dördüncü aşamada kelime köklerinin tespit edilmesine yönelik 63 kelime kökü tanımlanmıştır. Örneğin; elemanı, elemanlar, elemanların kelimeleri eleman kelimesi altında kodlanmıştır. Beşinci aşamada, n-gram olarak ifade edilen ve "belge_yönetim_sistemi” gibi sık tekrarlanan üçlü kelime grupları tespit edilmiştir. Veri madenciliği süreci sabit bir sırayla ilerlemez ve her bir aşama arasında sürekli gidip gelen işlemler söz konusudur (Pete vd., 2000, s.10). Bu bağlamda, anlamlı konu sayısının belirlenebilmesi için farklı parametreler kullanılmış, farklı kelime ve kelime gruplan filtre edilerek çok sayıda analiz gerçekleştirilmiştir. GDA denetimsiz bir tahmin yöntemidir ve analiz neticesinde ulaşılan sonuçların değerlendirilmesi için farklı ölçüm değerlerinden yararlanılmaktadır (McCallum, 2018, s. 1). Bu araştırmada dikkate alınan ölçüm değerlerinden ilki uyumluluk olarak ifade edilen "coherence"dir. Uyumluluk, konu altında değerlendirilen kelimelerin bir arada bulunma eğilimini göstermektedir. Büyük negatif değerler sıklıkla bir arada bulunmayan kelimeleri göstermekte; sıfira yakın değerler ise kelimelerin daha sık birlikte olma eğiliminde olduğunu ifade etmektedir. Corpus_dist; veri setindeki tüm belgeler sadece bir konu altında toplanması halinde, her bir konunun bu tek konuya ne kadar uzaklıkta olduğunu hesaplayan ölçüm değeridir. Yüksek değer konunun daha farklı olduğunu, düşük değer ise konunun genele daha benzer olduğunu göstermektedir. Exclusivity; konuyla ilgili en çok kullanılan kelimelerin ne kadar özel olduğunu ifade eden bir ölçümdür. Konu için en çok kullanılan kelimeler diğer konularda sık kullanılmıyorsa bu değer ilgili konu için yüksektir (McCallum, 2018, s.1). Perplexity, GDA yönteminde konu sayısının belirlenmesi için kullanılan ve basit anlamda, belirtilen konu sayısının ne ölçüde iyi tahmin edebildiğini ölçen değeridir. Düşük perplexity değeri ise konu sayısının daha anlamlı olduğunu ifade etmektedir (D. M. Blei vd., 2003, s. 1008).

GDA'da konu sayısının belirlenmesi araştırma sürecindeki en önemli aşamadır. GDA denetimsiz bir algoritmadır ve model çalışmadan önce optimum konu sayısı belirlenmemiştir (Zhou, Awasthi ve Stal-Le Cardinal, 2021, s. 5). Konu sayısının çeşitli tahmin yöntemleriyle belirlenmesi yerine araştırma kapsamında 
yorumlanabilecek bir biçimde tanımlanması daha etkili bir yöntem olarak görülmektedir (Chang, BoydGraber, Gerrish, Wang ve Blei, 2009, s.8; Kirilenko ve Stepchenkova, 2018, s. 8). Bu bağlamda, konu sayısının belirlenmesi için 50 konuya kadar model tekrarlanmıştır. Şekil 4'te perplexity değerlerine göre 50 konu için dağılım görülmektedir. Konu sayısının yüksek olması yorumlamayı zorlaştırmakta, az sayıda olması ise sadece genel konuların gösterilmesine sebebiyet vermektedir. Şekil 4'te optimum konu sayıs 7 olarak görülse de 11 konu başlı̆̆ını araştırma kapsamında daha ideal bir sayı olduğuna karar verilmiştir.

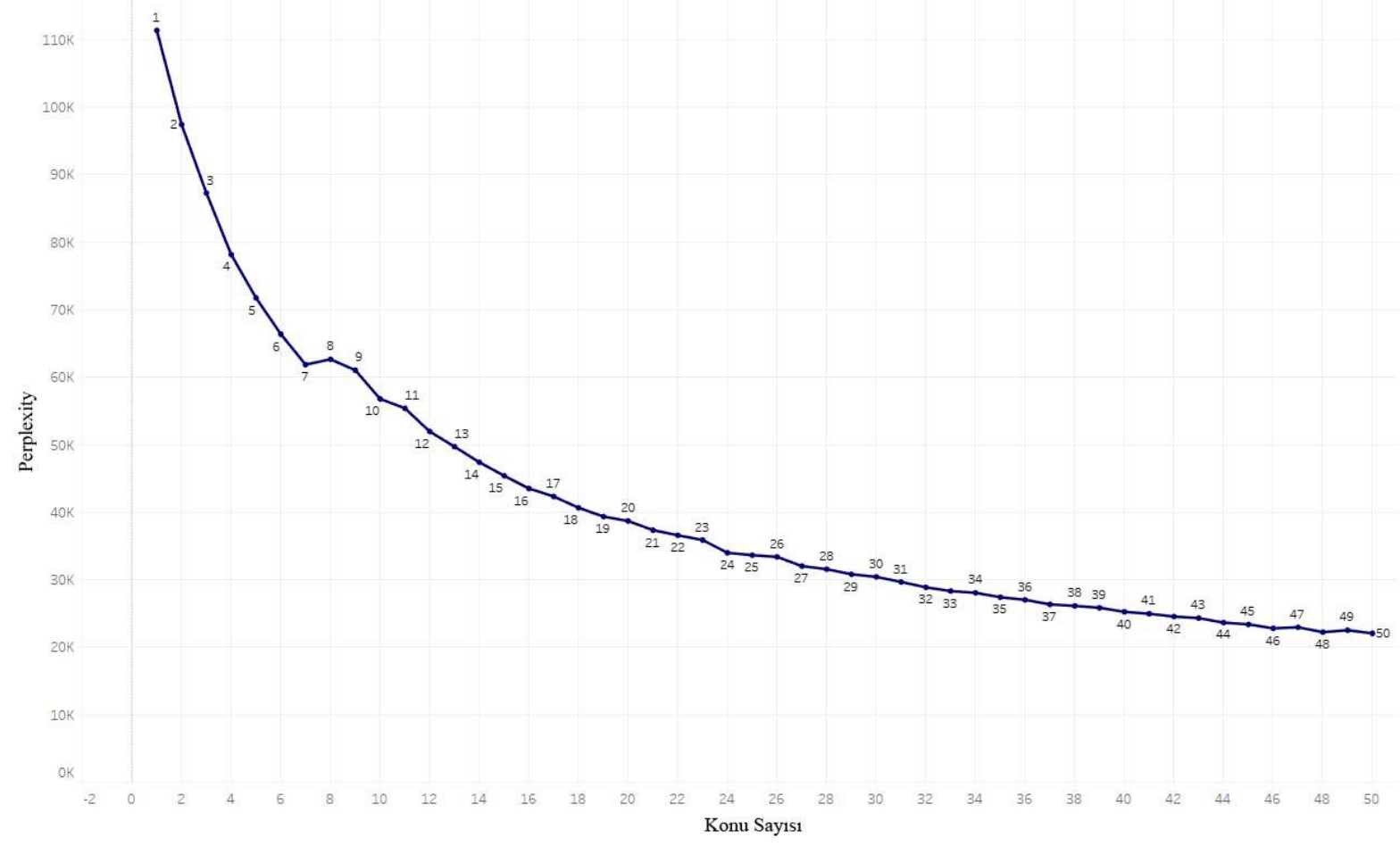

Şekil 4. Perplexity / Konu Sayısı Grafiği

Oluşturulan 11 konu için değerlendirme ölçümleri Tablo 8'de görülmektedir. Değerlendirme ölçümlerinde geçerlilik ya da güvenilirlik analizlerinde olduğu gibi net bir yargı söz konusu değildir. Bu değerlerin yüksek ya da düşük çıkmasının birçok nedeni olduğu ifade edilmektedir (McCallum, 2018, s. 1). Değerlendirme ölçümleri araştırma sürecinde tekrar eden analizlerde araştırmacıların modeli teşhis için kullandığ1 parametrelerdir. Nihai model için değerlendirme ölçümleri genel olarak incelendiğinde, uyumluluk (Coherence) açısından $\mathrm{K}_{3}$ ve $\mathrm{K}_{10}$ kapsamındaki kelimelerin diğer konulara göre bir arada bulunma eğiliminin görece fazla olduğu görülmektedir. Corpus_dist değerlerine göre ise, özellikle $\mathrm{K}_{3}$ ’ün görece daha genel bir konu başlğ̆ olabileceği söylenebilir. Exclusivity ölçümü değerlerine göre $K_{3}$ ve $\mathrm{K}_{10}$ ’un görece yüksek olması daha özel konular olabileceğini göstermektedir.

Tablo 8. GDA Değerlendirme Ölçümleri

\begin{tabular}{lccc}
\hline Konular & Coherence & Exclusivity & Corpus_Dist \\
\hline $\mathbf{K}_{\mathbf{1}}$ & $-90,8188$ & 0,6858 & 2,2939 \\
\hline $\mathbf{K}_{\mathbf{2}}$ & $-132,3816$ & 0,6941 & 2,4968 \\
\hline $\mathbf{K}_{\mathbf{3}}$ & $-80,3573$ & 0,7415 & 1,2205 \\
\hline $\mathbf{K}_{\mathbf{4}}$ & $-92,8858$ & 0,6971 & 2,3593 \\
\hline $\mathbf{K}_{\mathbf{5}}$ & $-90,6178$ & 0,6251 & 1,9876 \\
\hline $\mathbf{K}_{\mathbf{6}}$ & $-115,0555$ & 0,6471 & 2,5559 \\
\hline $\mathbf{K}_{\mathbf{7}}$ & $-119,1005$ & 0,7017 & 2,5064 \\
\hline $\mathbf{K}_{\mathbf{8}}$ & $-104,4500$ & 0,6755 & 2,5292 \\
\hline $\mathbf{K}_{\mathbf{9}}$ & $-127,5695$ & 0,6192 & 2,5102 \\
\hline $\mathbf{K}_{\mathbf{1 0}}$ & $-82,4852$ & 0,7498 & 2,3012 \\
\hline $\mathbf{K}_{\mathbf{1 1}}$ & $-94,1456$ & 0,6466 & 2,2932 \\
\hline
\end{tabular}

11 konu ve konuyu en iyi temsil ettiği tahmin edilen ilk 10 kelimenin coherence değerleri Şekil 5 'te verilmiştir. $\mathrm{K}_{1}$ konu başlığ $e$-Ticaret ve Paz̧arlama olarak tanımlanmışır. Tüketici araştırmaları ağırlıklı olmak üzere, pazarlama, e-ticaret ve sosyal medya konulu tez konuları bu başlık altında toplanmaktadır. Sistem Geliştirme ve Etkileri olarak isimlendirilen $\mathrm{K}_{2}$ konularının kurumsal kaynak planlama, kullanılabilirlik ve 
elektronik belge yönetim sistemi kelimelerinin ağırlıklı olduğu görülmektedir. $\mathrm{K}_{3}$, GDA ölçümleri dikkate alındığında diğger konulara göre daha genel yapıya sahip bir konu olarak Bilişim Sistemleri'nin Organizasyonlara Etkileri olarak tanımlanmıştır. Bu konu kapsamında çoğu tez özetinde anket yöntemi vurgusunun yapıldığ1 görülmektedir. $\mathrm{K}_{4}$ konusu Veri Madenciligi olarak tanımlanmaktadır. Algoritma kelimesi bu konuyu ifade eden en anlamlı kelimedir. Bu konu altında yer alan veri madenciliği, sınıflandırma kelimeleri yüksek, duygu analizi ve sosyal medya ise görece daha düşük sayıdadır. Birliktelik kelimesi bir veri analizi yöntemi olarak birliktelik kuralını temsil etmekte ve bu konu başlı̆ı altında yer almaktadır.

\begin{tabular}{|c|c|c|c|c|c|c|c|}
\hline \multicolumn{2}{|c|}{ [K $\left.\mathrm{K}_{1}\right]$ e-Ticaret ve Pazarlama } & \multicolumn{2}{|c|}{$\left[\mathrm{K}_{2}\right]$ Sistem Geliştirme ve Etkileri } & \multicolumn{2}{|c|}{$\begin{array}{c}\text { [K, BS'nin Organizasyonlara } \\
\text { Etkileri }\end{array}$} & \multicolumn{2}{|c|}{$\left[\mathrm{K}_{4}\right]$ Veri Madenciliği } \\
\hline Tüketici & 0.0 & Kurumsal Kaynak Planlama & 0.0 & İşletme & 0.0 & Algoritma & 0.0 \\
\hline Pazarlama & -0.97 & Kullanılabilirlik & -1.69 & Hizmet & -1.14 & Veri Madenciliğ $i$ & -0.80 \\
\hline e-Ticaret & -2.37 & EBYS & -3.93 & Performans & -1.65 & Kredi & -2.35 \\
\hline Online & -1.73 & Proje Yönetimi & -3.01 & Bilgi_Sistem & -2.29 & Sinuflandirma & -1.16 \\
\hline Alışveriş & -2.00 & Girișimcilik & -3.93 & Anket & -1.60 & Kural & -3.33 \\
\hline Marka & -3.93 & Bilgi Güvenliği & -3.93 & İletişim & -2.17 & Tahmin & -2.42 \\
\hline Sosyal Medya & -2.49 & Yazilim_Proje & -3.86 & Çalışan & -2.04 & Makine Öğrenmesi & -4.01 \\
\hline Satin Alma & -2.14 & İç_Kontrol & -3.68 & Yönetici & -2.17 & Sosyal Medya & -3.33 \\
\hline Dijital & -4.31 & Yeșil Bilișim & -3.93 & Etkin & -2.11 & Duygu Analizi & -3.33 \\
\hline Dijital Pazarlama & -4.31 & Belge_Yönetim_Sistemi & -3.93 & Teknolojik & -2.52 & Birliktelik & -3.68 \\
\hline \multicolumn{2}{|c|}{$\begin{array}{l}{\left[\mathrm{K}_{5}\right] \text { İnsan Kaynakları }} \\
\text { Yönetimi }\end{array}$} & \multicolumn{2}{|c|}{$\left[\mathrm{K}_{6}\right]$ Organizasyonel Değişim } & \multicolumn{2}{|c|}{$\left[\mathbf{K}_{7}\right]$ Alana Özel Çalışmalar I } & \multicolumn{2}{|c|}{ [K $\left.\mathrm{K}_{8}\right]$ Güvenlik } \\
\hline Çalışan & 0.0 & Kültür & 0.0 & Sağlık & 0.0 & Güvenlik & 0.0 \\
\hline Anket & -0.66 & Endüstri 4.0 & -2.09 & Tedarik Zinciri Yönetimi & -2.49 & Siber & 1.39 \\
\hline Performans & -1.29 & Üretim & -3.68 & Bulut Bilişim & -4.07 & Geçiş & 3.01 \\
\hline Ölçek & -1.76 & Bilgi_Yönetim & -2.09 & Yönetici & -3.46 & Kontrol_Sistem & 3.01 \\
\hline Örgütsel & -2.04 & Servis & -3.68 & Blokzinciri & -4.07 & Kart & -3.46 \\
\hline Demografik & -1.01 & Örgüt & -3.68 & Yerel & -4.07 & Geliştirme_Süreç & -3.57 \\
\hline İKY & -3.64 & Değișim & -3.68 & Nesnelerin İnterneti & -3.57 & Yazilım_Geliștirme & -3.46 \\
\hline Mobil Banka & -4.01 & Sanayi & -3.46 & Lojistik & -3.57 & Akıll__Kart & -3.57 \\
\hline Etik & -3.46 & Arge & -3.46 & Hastane & -3.57 & Web_Sitesi & -4.41 \\
\hline Güven & -3.68 & Kalite Yönetimi & -3.68 & Sağlik_Hizmet & -3.57 & Kart_Sistem & -3.57 \\
\hline \multicolumn{2}{|c|}{$\begin{array}{l}\left.\text { [K } \mathrm{K}_{9}\right] \text { Alana Özel Çalışmalar } \\
\text { II }\end{array}$} & \multicolumn{2}{|c|}{$\left[K_{10}\right]$ Eğitim ve Öğretim } & \multicolumn{2}{|c|}{ [K $\left.\mathrm{K}_{11}\right]$ Tahmin ve Karar Destek } & & \\
\hline Seçim & 0.0 & Öğrenme & 0.00 & Tahmin & 0.0 & & \\
\hline Tedarikçi & -2.00 & Uzaktan_Öğretim & -1.00 & Karar_Destek_Sistem & -2.41 & & \\
\hline e_Devlet & -4.54 & Öğretim_Eleman & -2.04 & Elektrik & -2.41 & & \\
\hline Analitik Hiyerarși & -3.01 & Ders & -1.56 & Finansal & -3.86 & & \\
\hline Sabit & -3.77 & e_Öğrenme & -3.46 & Hisse & -3.86 & & \\
\hline Online & -4.54 & Mesleki & -3.57 & Algoritma & -2.27 & & \\
\hline Portföy & -3.77 & Yetkinlik & -3.57 & Bitcoin & -3.86 & & \\
\hline e_Devlet_Uygulama & -4.54 & Sinif & -1.99 & Yapay_Sinir & -3.57 & & \\
\hline Şehir & -3.77 & Ölçek & -1.84 & Derin_Öğrenme & -3.86 & & \\
\hline Oyun & -4.54 & Lisans & -3.57 & Ögrenme & -3.86 & & \\
\hline
\end{tabular}

\section{Şekil 5. Konu Başliklar Tabmini ve Kelimeler}

$\mathrm{K}_{5}$, İnsan kaynakları yönetimi olarak tanımlanmış olan konu başlğıdır. Bu konuyu temsil eden en önemli kelimenin çalısan olduğu görülmektedir. Ayrıca, anket kelimesi $\mathrm{K}_{3}$ 'te olduğu gibi bu konu altında yer alan tez özetlerinin büyük bir bölümünde yer almaktadır. $\mathrm{K}_{6}$, Organizasyonel Değisisim olarak tanımlanmaktadır. $\mathrm{K}_{7}$, sağlık kelimesinin en güçlü kelime olarak yer aldığı ve farklı alanları da içeren bir yap1 olarak Alana Özel Çalş̧malar şeklinde isimlendirilmiştir. Tedarik zinciri yönetimi, bulut bilişim, blok zinciri ve nesnelerin interneti kelimeleri bu konu kapsaminda yer alan özetlerde bulunan baz1 kelimelerdir. $\mathrm{K}_{8}$, Güvenlik olarak tanımlanmışır. Önemli bir bölümü siber güvenlik olmak üzere teknik yapıya sahip akıllı kart ve geçiş sistemi bağlamındaki özetlerden oluşmaktadır. $K_{9}$ başlığındaki konularının, bir diğer özel alan çalışmalarından oluştuğu düşünülmektedir. Seçim kelimesinin en güçlü yapıya sahip olduğu bu başlıkta tedarikçi ikinci önemli kelimedir. Ayrıca, e-devlet uygulamaları, sabit (oran, çarpan), portföy, şehir ve oyun gibi farklı kelime içeren özetlerin bu konu başlı̆̆ altında toplandığı görülmektedir. $\mathrm{K}_{10}$, konu başlığındaki tez özetlerinin net bir şekilde eğitim ve öğretim içerikli bir yapıya sahip olduğu tespit edilmiştir. Bu konuyu en iyi temsil eden kelime "öğrenme"dir. Son olarak, $\mathrm{K}_{11}$ konusunun tahmin ve karar destek çizgisinde bir yapı izlediği düşünülmektedir. Elektrik, finansal, hisse, bitcoin gibi alt konu başlıklarını ve yapay sinir, derin öğrenme gibi makine öğrenmesi yöntemlerini içerdiği görülmektedir. 


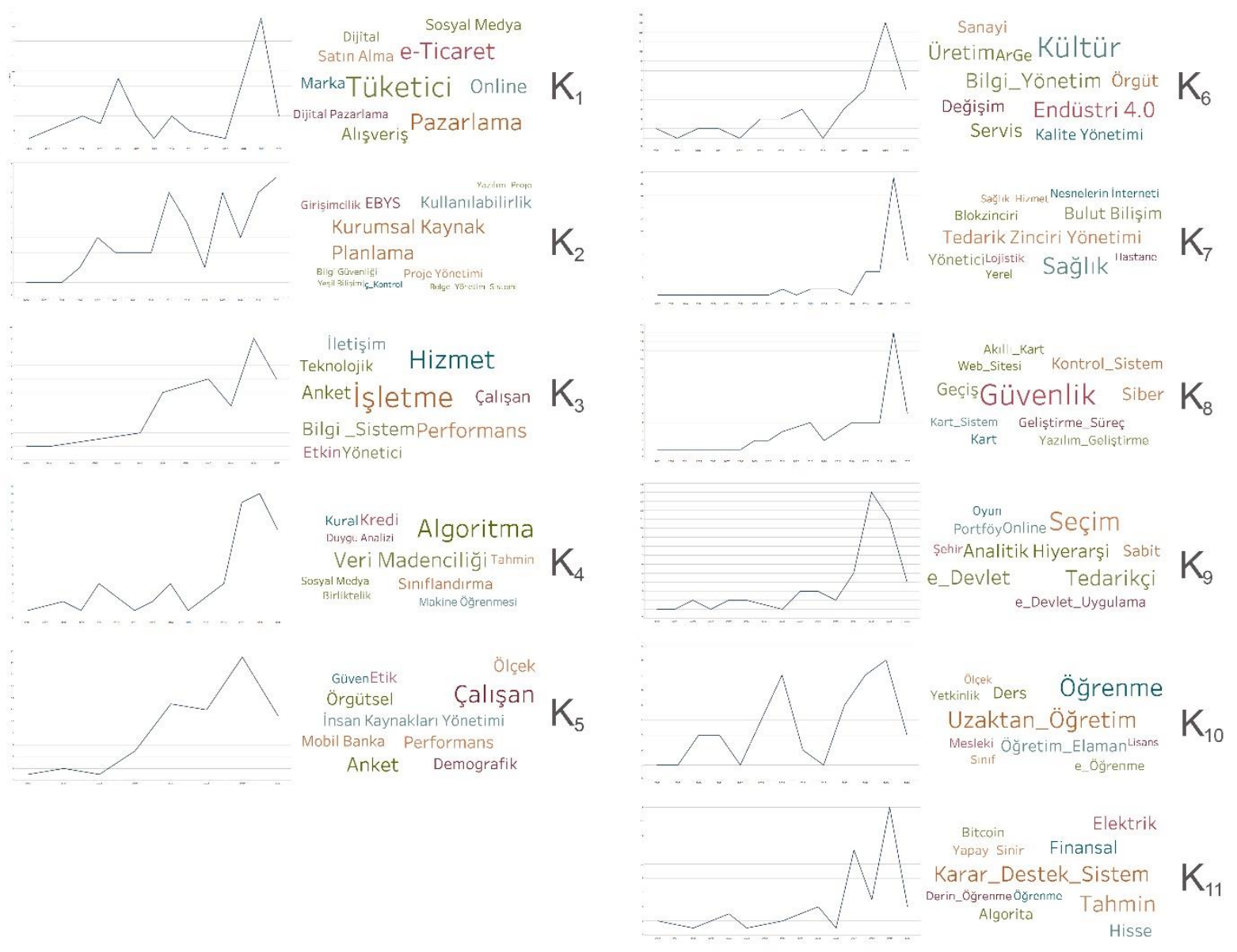

Şekil 6. Yıllara Göre Konu Dă̆gllm Tabminleri ve Kelime Bulutlar

Şekil 6'da 2002 ve 2020 yilları arası konu dağılım tahminleri incelendiğinde, $K_{7}, K_{8}, K_{9}$ ve $K_{11}$ kapsamındaki konuların özellikle son yıllarda artış trendi içinde olduğu görülmektedir.

\section{Sonuç ve Öneriler}

$\mathrm{Bu}$ araştırmada, Türkiye'de YBS anabilim dalı ve bilim dalında tamamlanan 574 lisansüstü tez çalışmasının GDA yöntemiyle konu modellemesi hazırlanarak çalışma konuları ve eğilimlerinin belirlenmesi amaçlanmıştır. Yürütülen analizler sonucunda, lisansüstü tez çalışmalarının 11 konu başlı̆ğ altında genel bir dağılımı çıkarılmışı̧ı. Sonuçlar, Abedin vd., (2020, s. 1), Beydoun vd. (2019, s. 491) ve Jeyaraj ve Zadeh $(2020$, s. 15) tarafından yürütülen uluslararası araştırmalarla önemli oranda benzerlik göstermekle beraber özellikle uzaktan eğitim ve insan kaynakları yönetimi konularının Türkiye'de daha yoğun çalışıldığını ortaya koymaktadır. Ayrıca, analiz bulguları neticesinde birincil kaynak veri toplama yöntemi olan anketin oldukça sık kullanıldığı ifade edilebilir.

Araştırma bulguları $\mathrm{K}_{7}, \mathrm{~K}_{8}, \mathrm{~K}_{9}$ ve $\mathrm{K}_{11}$ olarak isimlendirilen araştırma konularının son yıllarda yükselişte olduğuna dikkati çekmektedir. $K_{7}$ konu başlğını oluşturan kelime kümesi incelendiğinde ön plana çıkan en güçlü kelimenin "sağllk" olduğu görülmektedir. Tedarik zinciri yönetimi, lojistik, blok zincir, yerel yönetim, hastane, nesnelerin interneti ve bulut bilişim temalı araştırmaların bu yapıyı oluşturması muhtemeldir. Nesnelerin interneti uluslararası literatürde de son yılların araştırma konuları arasındadır (Beydoun vd., 2019, s. 491; Coşkun vd., 2019, s. 186). Özköse (2017, s. 101) ve Aytaç (2020, s. 53) lisansüstü tezlerle ilgili yaptıkları analizlerde bulut bilişim konusunun son yıllarda önemli bir çalışma konusu olarak görüldüğünü belirtilmektedir.

Açık bir biçimde güvenlik konusunu oluşturan $\mathrm{K}_{8}$ kümesiyle ilgili bulgular, bu kavramın son yıllarda tamamlanan lisansüstü tezlerde çalışıldığını göstermektedir. Bu yapıyla ilgili olarak siber güvenlik, web sitesi, yazılım geliştirme ve kart-sistem kelimeleri dikkat çeken temalardır. Bulgular, Alma vd. (2017, s. 5) tarafindan Türkiye'de yürütülmüş olan araştırma sonuçlarıyla farkllılı göstermektedir. Çalışmada bilgi 
güvenliği konulu çalışmaların toplam çalışmalara oranı $\% 3,7^{\prime}$ dir. Lisansüstü tezlerle ilgili hazırlanan çalısmalarda ise bilgi güvenliği konusunun ön plana çıkmadı̆̆ı görülmektedir. YÖK’ün kritik teknoloji alanları düşünüldüğünde, bu hususun YBS disiplini için önemli bir gelişme olduğu düşünülmektedir. Diğer yandan, uluslararası literatür de Jeyaraj ve Zadeh $(2020$, s. 15) çevrimiçi güvenlik konusunun son yllarda yapılan çalışmaların odağı olduğunu belirtmektedir.

$\mathrm{K}_{9}$ kümesinde en güçlü yapiya sahip kelimelerin seçim ve tedarikçi olduğu düşünüldüğünde bu yapının karar vermeyle ilgili çalışmalarla ilişkili olduğu düşünülmektedir. e-Devlet ve uygulamalarının bu kavramlarla birlikteliği, bu hususlara odaklanan tezlerin ayrıca nitel yöntemlerle incelenmesi gerektiğini göstermektedir. Karar verme konusunun Türkiye özelinde yapılan çalışmalarda sıklıkla çalışıldığ1 diğer araştırmalar tarafindan da vurgulanmaktadır (Alma vd., 2017, s. 6; Aytaç, 2020, s. 53; Yarlikas, 2015, s. 141).

Tahmin-karar destek olarak isimlendirilen $\mathrm{K}_{11}$ konu başlı̆̆ ise son ylllarda daha yoğun çalışılan konu başılılarından biridir. Yapay sinir ağları, derin öğrenme ve öğrenme kelimelerinin mevcudiyeti karar destek sistemlerinin artık daha zeki tekniklerle desteklenme eğilimine paralel olarak araștırma konularının da değişimini göstermektedir. Daha önce yapılan çalsşmalardan sadece Aytaç, (2020, s. 53) kısıtlı da olsa bu konuların çalışıldığı ortaya koymuştur. Coşkun vd., (2019, s. 186) tarafından yaklaşık 150.000 makalenin analiz edildiği çalışma uluslararası literatürün çalışma konuları olarak yapay zeka, makine öğrenmesi, algoritmalar ve öznitelik seçimi anahtar kelimelerinin sıklığına ve gelişmekte olan trende dikkati çekmektedir. Bu bağlamda, ulaşılan bulgu önemlidir ve alan için olumlu bir gelişme olduğu düşünülmektedir.

Veri madenciliği olarak tanımlanan $\mathrm{K}_{4}$ kümesinde yer alan algoritma, veri madenciliği, sınıflandırma, makine öğrenmesi, sosyal medya ve tahmin kelimeleri uluslararası literatürün işaret ettiği YBS alanının önemli güncel konuları olarak dikkat çekmektedir. Kritik teknolojiler ve öncelikli alanlar politikaları da dikkate alındığında, bu hususların YBS araştırmalarında daha çok odaklanılması gereken konular olduğu düşünülmektedir.

Ağırlıklı olarak çalışılan konulardan yapay sinir ağları, derin öğrenme, makine öğrenmesi, bulut bilişim, siber güvenlik ve nesnelerin interneti gibi konular hem uluslararası literatürün gelişimiyle uyum halinde olmak hem de ulusal politikalara hizmet etmek bakımından oldukça önem taşımaktadır. Ön plana çıkan konular kadar, bu konuların tezlerde ele alındığı bağlam da önem taşımaktadır. Detaylı olarak incelenen ve farklı disiplinlere daha yakın olan bazı tezlerde, yapay sinir ağları, makine öğrenmesi, duygu analizi ve derin öğrenme gibi yaklaşımların sadece yöntem olarak kullanıldığı tespit edilmiştir. Seçim, tedarikçi ve analitik hiyerarşi kelimelerinin sıklığı yine tedarikçi seçimiyle ilişkili olarak kullanılan sayısal yöntemlerin yönetim bilişim sistemleri bölümlerinde sıklıkla çalışıldığını göstermektedir.

Bu çerçevede, bazı tezlerin yönetim bilişim sistemleri disiplinine katkısı sınırlıdır. Benzer şekilde, algoritmalar ve veri madenciliği uygulamalarının da pazarlama, finans ve üretim gibi alanlardaki çeşitli problemlere çözüm bulmak amacıyla kullanılması yine bu tezlerin yönetim bilişim sistemleri disipliniyle doğrudan ilişkisini sorgulanabilir hale getirmektedir. Alana orijinal katkının sadece güncel teknikler ve yöntemleri kullanarak tahmin, sınıflandırma veya farklı disiplinlerle ilişkili problemlere çözüm üreterek değil, teorik altyapının da güçlendirilerek olacağı düşünülmektedir. Yönetim bilişim sistemleri disiplininin temel odağı olan bilişim sistemlerinin geliştirilmesi ve etkileriyle ilişkili olan kavramların göreceli olarak daha az çalışılmış olması önemli bir bulgudur ve gelecekte yapılacak olan tezlerde ve bilimsel çalışmalarda dikkate alınmalıdır. Örneğin; kullanılabilirlik, proje yönetimi ve sistem geliştirme kavramları oldukça sınırlı sayıdaki tezde ele alınmıştır. Kullanılabilir teknolojilerin ve sistemlerin tasarlanması ve kullanıcı merkezli tasarımların özelliklerinin irdelenmesi bireylerin teknolojiyle etkileşimini artırmak bakımından oldukça kritiktir. Bu bağlamda, insan-bilgisayar etkileşimi odaklı konuların araştırılması hem kavramsal hem de deneysel çalışmaların üretilmesi alandaki mevcut çalış̧alarla ilgili gelişime açık bir husustur. Benzer şekilde, dijitalleşme, dijital dönüşüm, dijital okuryazarlık ve dijital uçurum gibi kavramlara az rastlanmışıtır veya bu kelimeler hiç tespit edilememiştir. Yerel organizasyonların mevcut durumlarının belirlenmesi, dijitalleşme ve dijital dönüşümle ilgili atılan adımlar ve önündeki engeller, organizasyonlar ve bireyler arasındaki dijital uçurum ve farklı grupların dijital okuryazarlığını ele alan çalışmalar, günümüzün öncelikli ihtiyaçlarına cevap verilmesi bakımından önem taşımaktadır. 


\section{Araştırma Kısıtları}

Araştırma kapsamında tanımlanan; $\mathrm{K}_{1}, \mathrm{~K}_{2}, \mathrm{~K}_{3}, \mathrm{~K}_{4}, \mathrm{~K}_{5}, \mathrm{~K}_{6}, \mathrm{~K}_{8}, \mathrm{~K}_{10}, \mathrm{~K}_{11}$, konularının oldukça açılayıcı ve anlamlı; $K_{7}$ ve $K_{9}$ konularının ise farklı konu başlıklarını içeren kısmen düzensiz bir dağılım sergilediği görülmektedir. Araştırmanın analiz aşamasında farklı konu sayıları farklı parametrelerle denenmiş ve 11 konu başlı̆ııın yorumlanabilme kolaylığı açısından uygun olduğuna karar verilmiştir. Sübjektif yargı içeren bu sürecin ve çalışmada yararlanılan denetimsiz tahmin modeli sonuçlarının sınanması mümkün değildir. Bu bağlamda, sonuçların YBS alanında hazırlanan tezlerin gerçek konu dağılımını göstermesi olanaksızdır. Tez özetleri için standart bir yapının olmaması, yazım hataları, farklı dillerde kullanılan kelimeler ya da gereksiz tekrarlar gibi birçok faktör kelime ve belge dağılımlarını etkilemekte ve sonuçları çarpıtmaktadır. $\mathrm{Bu}$ araştırmada dikkate alınan özetlere herhangi bir müdahale yapılmamış ve analize olduklan biçimde dahil edilmiştir.

$\mathrm{Bu}$ araştırma nitel analiz yöntemleri için bir alternatif olarak hazırlanmıştır ve YBS disiplini için genel bir konu dağılım tahmini sunmaktadır. Bu bağlamda, araştırma YBS alanında çalışmak isteyen öğrenci ve araştırmacılara yol göstermek ve fikir vermeyi amaçlamaktadır. Bibliyometrik çalışmaların farklı algoritmalar kullanarak hazırlanması ve sonuçların mukayese edilmesi Türkiye'de YBS disiplini için daha gerçekçi eğilimlerin tespit edilmesini sağlayacaktır.

\section{Etik Beyan}

"Yönetim Bilisim Sistemleri Disiplininde Hažrlanan Lisansüstü Tęৃlerin Giz̨li Dirichlet Ayrm Algoritmasıyla Konu Modellemesi" başlıklı çalışmanın yazım sürecinde bilimsel kurallara, etik ve alıntı kurallarına uyulmuş; toplanan veriler üzerinde herhangi bir tahrifat yapılmamış ve bu çalışma herhangi başka bir akademik yayın ortamına değerlendirme için gönderilmemiştir. Bu araştırma doküman incelemesine dayalı olarak yapıldığından etik kurul kararı zorunluluğu bulunmamaktadır.

\section{Kaynakça}

Abedin, B., Jafarzadeh, H. ve Olszak, C. M. (2020). Thirty six years of information systems management: A Bibliometric and thematic analysis. Information Systems Management, 1-14. https://doi.org/10.1080/10580530.2020.1781987

Ackoff, R. L. (1999). Ackoff's best. New York: John Wiley \& Sons.

Alan, H. (2019). Disiplinler arası bir bilim dalı olma yolunda yönetim bilişim sistemleri ve işletme enformatiğinin temelleri. Celal Bayar Üniversitesi Sosyal Bilimler Dergisi, 17(2), 69-92. https://doi.org/10.18026/cbayarsos.475441

Alavi, M., Carlson, P. ve Brooke, G. (1989). The ecology of mis research: A twenty year status review. ICIS 1989 Proceedings. 6. Ss. 363-374 Erişim adresi: http://aisel.aisnet.org/icis1989/6

Alma, B., Koç, T. ve Coşkun, E. (2017). Analysis of research characteristics of MIS discipline in Turkey. ICTS in Global Development. Erişim adresi: https://aisel.aisnet.org/amcis2017/ICTs/Presentations/11/

Aytaç, A. M. (2020). Türkiye’de yönetim bilişim sistemleri alannnda yapılan akademik şalş̧malarda yönelimler (Yüksek lisans tezi) Ufuk Üniversitesi.

Barki, H., Rivard, S. ve Talbot, J. (1988). An information systems keyword classification scheme. MIS Quarterly: Management Information Systems, 12(2), 299-310. https://doi.org/10.2307/248855

Bastani, K., Namavari, H. ve Shaffer, J. (2019). Latent dirichlet allocation (LDA) for topic modeling of the CFPB Consumer Complaints. Expert Systems with Applications 127. Elsevier Ltd: 256-71. doi:10.1016/j.eswa.2019.03.001

Bellinger, G., Castro, D. ve Mills, A. (n.d.). Data, information, knowledge, and wisdom. 2004 Erişim tarihi 24 Şubat 2021, Erişim adresi: http://www.systems-thinking.org/dikw/dikw.htm

Benbasat, I., ve Weber, R. (1996). Research commentary: Rethinking "diversity" in information systems research. Information Systems Research, 7(4), 389-399. https://doi.org/10.1287/isre.7.4.389

Bensghir, T. K. (2002). Türkiye'de yönetim bilişim sistemleri disiplininin gelişimi üzerine düşünceler. Amme İdaresi Dergisi, 35(1), 77-103.

Beydoun, G., Abedin, B., Merigó, J. M., ve Vera, M. (2019). Twenty Years of Information Systems Frontiers. Information Systems Frontiers, 21(2), 485-494. https://doi.org/10.1007/s10796-019-09925-x

Blei, D. M., Ng, A. Y. ve Jordan, M. I. (2003). Latent Dirichlet Allocation David. Journal of Machine Learning Research, 3, 993-1022.

Brodie, I. ve Brodie, L. (2009). A knowledge-1nformation-data concept model for engineering education. Australasian Journal of Engineering Education, 15(3), 137-144. https://doi.org/10.1080/22054952.2009.11464030

Campbell-Kelly, M. (1996). Information Technology and Organizational Change in the British Census, 1801-1911. In Information Systems Research, 7(1), 22-36.

Chang, J., Boyd-Graber, J., Gerrish, S., Wang, C. ve Blei, D. M. (2009). Reading tea leaves: How humans interpret topic models. Advances in Neural Information Processing Systems 22 - Proceedings of the 2009 Conference, 288-296. 
Coşkun, E., Özdağoğlu, G., Damar, M. ve Çallı, B. A. (2019). Scientometrics-based study of computer science and information systems research community macro level profiles. Proceedings of the 12th LADIS International Conference Information Systems 2019, IS 2019, April, 180-188. https://doi.org/10.33965/is2019_2019051023

Daim, T. U., Rueda, G., Martin, H. ve Gerdsri, P. (2006). Forecasting emerging technologies: Use of bibliometrics and patent analysis. Technological Forecasting and Social Change, 73(8), 981-1012. https://doi.org/10.1016/j.techfore.2006.04.004

Emre, İ. E. ve Kıran, S. (2019). Türkiye'deki yönetim bilişim sistemleri ve işletme enformatiği bölümlerinin incelenmesi. 6. International Management Information Systems Conference "Connectedness and Cybersecurity," October 2019. ss. $423-433$

Hoppe, A., Seising, R., Nürnberger, A. ve Wenzel, C. (2011). Wisdom-the blurry top of human cognition in the dikw-model? Proceedings of the 7th Conference of the European Society for Fuzay Logic and Technology, EUSFLAT 2011 and French Days on Furzy Logic and Applications, LFA 2011, 1(1), 584-591. https://doi.org/10.2991/eusflat.2011.91

Jelodar, H., Wang, Y., Yuan, C., Feng, X., Jiang, X., Li, Y. ve Zhao, L. (2019). Latent dirichlet allocation (LDA) and topic modeling: models, applications, a survey. Multimedia Tools and Applications, 78(11), 15169-15211. https://doi.org/10.1007/s11042-018-6894-4

Jeyaraj, A. ve Zadeh, A. H. (2020). Evolution of information systems research: Insights from topic modeling. Information and Management, 57(4), 103207. https://doi.org/10.1016/j.im.2019.103207

Keen, P. G. W. (1980). Mis Research: Reference Disciplines and a Cumulative Tradition. 9-18.

Kherwa, P. ve Bansal, P. (2018). Topic modeling: A comprehensive review. ICST Transactions on Scalable Information Systems, $O(0), 159623$ 1-16. https://doi.org/10.4108/eai.13-7-2018.159623

Kirilenko, A. P. ve Stepchenkova, S. (2018). Tourism research from its inception to present day: Subject area, geography, and gender distributions. PLOS ONE, 13(11), 1-20. https://doi.org/10.1371/journal.pone.0206820

La Paz, A., Merigó, J. M., Powell, P., Ramaprasad, A., ve Syn, T. (2020). Twenty-five years of the Information Systems Journal: A bibliometric and ontological overview. Information Systems Journal, 30(3), 431-457. https://doi.org/10.1111/isj.12260

Landry, M. ve Banville, C. (1992). A disciplined methodological pluralism for mis research. Accounting, Management and Information Technologies, 2(2), 77-97. https://doi.org/10.1016/0959-8022(92)90002-A

Laudon, K. C. ve Laudon, J. P. (2020). Management information systems : Managing digital firm (16th ed.). Pearson.

Liew, A. (2007). Understanding data, information, knowledge and their inter-relationships. Retrieved February 8, 2021, Erişim adresi: http://www.tlainc.com/articl134.htm

Maier, D., Waldherr, A., Miltner, P., Wiedemann, G., Niekler, A., Keinert, A., Pfetsch, B., Heyer, G., Reber, U., Häussler, T., Schmid-Petri, H., ve Adam, S. (2018). Applying LDA Topic Modeling in Communication Research: Toward a Valid and Reliable Methodology. Communication Methods and Measures, 12(2-3), 93-118. https://doi.org/10.1080/19312458.2018.1430754

McCallum, A. (2018). Topic model diagnostics. Erişim adresi: http://mallet.cs.umass.edu/diagnostics.php

Özkoç, E. E. (2019). Türkiye'de yönetim bilişim sistemleri çalışmalarının bibliyometrik yapısı ve sosyal ağ analizi ile çözümlemesi. YDÜ Sosyal Blmler Dergisi, XII(1), 25-43.

Özköse, H. (2017). Yönetim bilişim sistemleri alanmm türkiye ve dünya'daki bibliyometrik analizi ve haritası (Doktora Tezi). Gazi Üniversitesi.

Palvia, P., Mao, E., Salam, A. F. ve Soliman, K. S. (2003). Management information systems research: What's there in a methodology? Communications of the Association for Information Systems, 11(March). https://doi.org/10.17705/1cais.01116

Pete, C., Julian, C., Randy, K., Thomas, K., Thomas, R., Colin, S. ve Wirth, R. (2000). Crisp-Dm 1.0. In CRISP-DM Consortium (p. 76).

Rowley, J. (2007). The wisdom hierarchy: representations of the DIKW hierarchy. Journal of Information Science, 33(2), 163-180. https://doi.org/10.1177/0165551506070706

Rueda, G., Gerdsri, P., ve Kocaoglu, D. F. (2007). Bibliometrics and social network analysis of the nanotechnology field. Portland International Conference on Management of Engineering and Technology, 2905-2911. https://doi.org/10.1109/PICMET.2007.4349633

Stemler, S. (2001). An overview of content analysis. Practical assessment, research, and evaluation. ScholarWorks@UMass_Amberst, 7(17),2000-2001.

Yarlikas, S. (2015). Yönetim Bilişim Sistemleri Disiplininin Türkiye’deki Mevcut Durumu Üzerine Bir İnceleme. Journal of Higher Education and Science, 5(2), 136. https://doi.org/10.5961/jhes.2015.116

Yükseköğretim Kurulu. (2020). Geleceğin Bilim Insanlar İçin "YÖK-GELECEK PROJESİ". Erişim adresi: https://www.yok.gov.tr/Sayfalar/Haberler/2020/yok-gelecek-projesi.aspx

Zhou, R., Awasthi, A. ve Stal-Le Cardinal, J. (2021). The main trends for multi-tier supply chain in Industry 4.0 based on Natural Language Processing. Computers in Industry, 125, 103369. https://doi.org/10.1016/j.compind.2020.103369

Zins, C. (2007). Conceptual approaches for defining data, information, and knowledge. Journal of the American Society for Information Science and Technology, 58(4), 479-493. https://doi.org/10.1002/asi.20508 


\section{EXTENDED ABSTRACT}

The disciplines that affect the theories developed in the field, and the identification of the existing topic diversity have all been extensively discussed in the academic literature since the Management Information Systems (MIS) was first defined as a discipline. In this study, 574 postgraduates' theses completed between 2002 and 2020 in the Department of MIS were analyzed using the Hidden Dirichlet Discrimination algorithm, which is a text mining method.

As a result of the analysis, it is predicted that postgraduates' theses can be clustered under 11 topics, that are e-Commerce and Marketing $\left(\mathrm{K}_{1}\right)$, System Development and Effects $\left(\mathrm{K}_{2}\right)$, Effects of Information Systems on Organizations $\left(\mathrm{K}_{3}\right)$, Data Mining $\left(\mathrm{K}_{4}\right)$, Human Resources Management $\left(\mathrm{K}_{5}\right)$, Organizational Change $\left(K_{6}\right)$, Field-Specific Studies I $\left(K_{7}\right)$, Field-Specific Studies II $\left(K_{9}\right)$, Security $\left(K_{8}\right)$, Education and Training $\left(\mathrm{K}_{10}\right)$, Forecasting and Decision Support $\left(\mathrm{K}_{11}\right)$. The similarities and differences of the results are discussed in the context of the national and international literature. The findings are substantially similar to international studies conducted by Abedin et al. (2020, p.1), Beydoun et al. (2019, p.491), and Jeyaraj and Zadeh (2020, p.15). Furthermore, education (especially distance learning) and human resource management, which appear to be topics more studied in Turkey. Besides, the questionnaire, as a datagathering tool, was discovered to be the primary method used by most of the postgraduate theses.

Findings show that topics named $K_{7}, K_{8}, K_{9}$, and $K_{11}$ have been on the rising trend in recent years. When the keywords constituting the $\mathrm{K}_{7}$ theme are analyzed, it can be seen that the most powerful word that stands out is health. This topic is likely to be established by supply chain management, logistics, blockchain, local government, hospital, internet of things, and cloud computing. Internet of Things (IoT) has been one of the most popular research topics in the international literature in recent years (Beydoun et al., 2019, p.191; Coşkun et al., 2019, p.186). Özköse (2017, p.101) and Aytaç (2020, p.53) indicate that cloud computing has been seen as an important study topic in recent years, in their results.

Findings of the $\mathrm{K}_{8}$ cluster, which constitutes the issue of security, show that this concept has been studied in postgraduate theses completed in recent years. Regarding this structure, the words cybersecurity, website, software development, and card-system are the themes that attract attention.

The findings of this research vary with the results of the study conducted in Turkey by Alma vd. $(2017, \mathrm{p} 5)$. The ratio of studies on information security to total studies was determined as $3.7 \%$ in their research and it is not mentioned that the topics of information security come to the fore in the studies prepared on the postgraduate theses. Considering the critical technology areas of YÖK (Council of Higher Education), it is thought that this is an important development for the MIS discipline. On the other hand, international literature (Jeyaraj \& Zadeh, 2020, p.15) also states that online security is the focus area of recent studies.

The strongest words in the $\mathrm{K}_{9}$ topic are choice and supplier. This topic is thought to be related to decision-making studies. The $\mathrm{K}_{11}$ topic, called prediction-decision support, is one of the topics that have been studied more intensely in recent years. The presence of artificial neural networks, deep learning, and learning words shows the change in research topics in parallel with the trend of decision support systems to be supported by more intelligent techniques. Only Aytaç (2020, p.53) from previous studies has revealed that these issues have been studied, albeit in a limited way. The study by Coşkun et al., (2019, p.186), in which approximately 150,000 articles were analyzed, draws attention to the frequency of artificial intelligence, machine learning, algorithms, and feature selection keywords and the developing trend as the study topics of international literature. In this context, the finding achieved is important and is considered to be a positive development for the field.

The algorithm, data mining, classification, machine learning, social media, and prediction words in the $\mathrm{K}_{4}$ cluster, which is defined as data mining, attract attention as important current issues in the MIS field, which is also pointed out by the international literature. Considering the critical technologies and priority areas policies, it is thought that these issues should be focused more on MIS research.

Defined within the scope of the research; It is seen that the subjects of $K_{1}, K_{2}, K_{3}, K_{4}, K_{5}, K_{6}, K_{8}$, $\mathrm{K}_{10}, \mathrm{~K}_{11}$ are quite descriptive and meaningful, while $\mathrm{K}_{7}$ and $\mathrm{K}_{9}$ subjects exhibit a partially irregular distribution that includes different topics. In the analysis phase of the research, different topic numbers were tested with different parameters and it was decided that 11 topics were suitable for ease of interpretation. It is not possible to test this process involving subjective judgment and the results of the 
ÇALLI, ÇALLI ve ALMA ÇALLI

Yönetim Bilişim Sistemleri Disiplininde Hazırlanan Lisansüstü Tezlerin Gizli Dirichlet Ayrımı Algoritmasıyla Konu Modellemesi

unsupervised estimation model used in the study. In this context, the results cannot show the real subject distribution of theses prepared in the field of MIS. Many factors such as the lack of a standard structure for thesis abstracts, spelling errors, words used in different languages, or unnecessary repetitions affect word and document distributions and distort the results. No intervention was made to the summaries considered in this study and were included in the analysis as they were. 